Running head: REACTIONS TO VICTIMIZATION

How Much Does Effortful Thinking Underlie Observers' Reactions to Victimization?

\author{
Annelie J. Harvey \\ Mitchell J. Callan \\ William J. Matthews \\ Department of Psychology, University of Essex, United Kingdom
}

In press, Social Justice Research

Author Note:

We thank Rael Dawtry and Laura Dunn for their assistance with data collection. Correspondence concerning this paper should be addressed to Annelie Harvey (aharve@essex.ac.uk) or Mitch Callan (mcallan@essex.ac.uk), Department of Psychology, University of Essex, Wivenhoe Park, Colchester, CO4 3SQ, United Kingdom. 


\begin{abstract}
From blaming to helping innocent victims, just-world research has revealed that observers react to victimization in a variety of ways. Recent research suggests that such responses to victimization require effortful thought, whereas other research has shown that people can react to these situations intuitively. Along with manipulating just-world threat, across 7 experiments we manipulated or measured participants' level of mental processing before assessing judgments of victim derogation, blame, willingness to help, and ultimate justice reasoning. The effect of just-world threat on these responses held constant over a range of manipulations/measures, suggesting that the processes involved in maintaining a belief in a just-world are not restricted to the rational, deliberative level of mental processing but also occur intuitively.
\end{abstract}

Keywords: belief in a just world; victimization; cognitive load; intuitive/experiential thinking; rational/deliberative thinking 


\section{How Much Does Effortful Thinking Underlie Observers' Reactions to Victimization?}

Lerner's (1980) just world theory posits that people need to believe that the world is a just and fair place in which people get what they deserve. Nearly 50 years of research has shown that believing in a just world is important enough to people that they will engage in numerous strategies to maintain a commitment to deservingness in the face of threat, such as compensating an innocent victim or, at times, derogating their character (see Hafer \& Bègue, 2005; Lerner, 1980). For example, in their classic experiment, Lerner and Simmons (1966) presented participants with a young woman who was ostensibly receiving electric shocks. When given the opportunity, virtually all participants voted to "reward" the victim by freeing her from enduring additional electric shocks. However, when there was no such opportunity to help and when the participants believed the woman's suffering would continue into a second phase of the experiment, they derogated her character, presumably as a means of interpreting her fate as deserved.

Since this early work, "just world" research has been largely dominated by investigations of victim derogation and blame (see Callan \& Ellard, 2010; Hafer \& Bègue, 2005), but Lerner (1980) proposed a number of other rational and non-rational strategies people can employ to maintain a commitment to justice and deservingness in the face of threat (see also Ellard, Harvey, \& Callan, in press). Recently, researchers have been turning their attention towards investigating these varied responses to undeserved suffering and misfortune. For example, among other strategies, observers have been shown to causally connect random bad outcomes to unrelated immoral behaviors (i.e., immanent justice reasoning; see Callan, Sutton, Harvey, \& Dawtry, 2014), perceive benefits in a victim's later life (i.e., ultimate justice reasoning; e.g., Anderson, Kay, \& Fitzsimons, 2010; Hafer \& Gosse, 2011; Warner, Vandeursen, \& Pope, 2012), compensate victims (e.g., Haynes \& Olson, 2006), or demonize the perpetrator (see Ellard, Miller, Baumle, \& Olson, 2002) to perceive justice and deservingness in response to misfortune and innocent suffering. For example, Anderson et al. (2010) found that participants whose just-world beliefs were first threatened in an unrelated context perceived greater enjoyment and meaning in the later life of a victim who suffered a great deal than for a victim who suffered only minimally. That is, rather than derogating his character, participants with a heightened concern for justice saw a "silver lining" in a misfortune by believing that the victim would be ultimately compensated for his suffering.

Although this research concerning people's reactions to injustice is broad and growing, much less is known about the modes of information processing that underlie these reactions. One basic issue concerns the roles that effortful, deliberative thinking and effortless, intuitive thinking play in people's reactions to injustice. That is, do people's responses to victimization require thoughtful deliberation or can they occur quite effortlessly?

Lerner and colleagues (Lerner, 1998; Lerner \& Clayton, 2011; Lerner \& Goldberg, 1999) argued that people's reactions to injustice occur intuitively and effortlessly, such that the recognition of an injustice "automatically elicits more or less elaborately scripted preconscious processes that typically include evaluations, thematic organizations of reactions, associated affect, and propensities to act" (Lerner \& Clayton, 2011, pg. 151). From this perspective, initial, schema-based reactions to injustice may lead people to, for example, intuitively connect a random bad outcome to the recipient's prior bad deeds (Callan et al., 2014), have the impulse to punish perpetrators of harm (Goldberg, J. S. Lerner, \& Tetlock, 1999), or spontaneously help a victim (Holmes, Miller, \& Lerner, 2002; Rand, Greene, \& Nowak, 2012). In support, a growing body of experimental research has suggested that people's reactions to victimization may occur intuitively - that is, without requiring a rational mind-set or much effortful thought (e.g., Aguiar, Vala, Correia, \& Pereira, 2008; Callan, 
Ferguson, \& Bindemann, 2013; Callan, Sutton, \& Dovale, 2010; Goldberg et al., 1999; Loseman \& van den Bos, 2012; Maas \& van den Bos, 2009; van Prooijen \& van de Veer, 2010). For example, adopting an eye-tracking methodology, Callan et al. (2013) found that the good (bad) behavior of characters within audio-visual scenes biased participants' eye gaze towards images of good (bad) outcomes before the actual outcomes were revealed verbally. This finding highlights how a concern for justice establishes an automatic preference for observers to expect outcomes that are consistent with what people deserve.

van den Bos and Maas (2009), however, argued that people require the mental capacity, effort, or ability to carefully consider an episode of injustice and to resolve the logical inconsistencies between believing in a just world and knowing that an innocent victim has suffered. Because the processes involved in resolving logically inconsistent beliefs are inherently propositional (Gawronski \& Bodenhausen, 2006), resolving an injustice may require effortful thought. To test this idea, van den Bos and Maas (2009) induced either an experiential/intuitive mind-set or a rational/deliberative mind-set by asking participants to consider how they would react to information while thinking intuitively or rationally. Participants were then exposed to scenarios that either ended with a high or low just-world threat (e.g., a robber who was not apprehended vs. a robber who was punished), and were asked to rate the blameworthiness of the victims. Consistent with their hypothesis, participants in a rational mind-set blamed the victims more under high than low just-world threat, whereas judgments of blame were unaffected by just-world threat when participants were in an experiential mind-set. In another experiment, the authors found that self-reported belief in a just world positively predicted victim blaming only when participants were in a rational (vs. intuitive/experiential) mind-set. These provocative results suggest that (at least) blaming an innocent victim requires effortful thought.

van den Bos and Maas's (2009) findings seem to stand in contrast to the research highlighted above that suggests people's reactions to injustice can occur without much effortful thought. On the whole, however, the research concerning people's intuitive reactions to injustice has largely focused on a variety of different experimental contexts (e.g., anticipatory eye-movements within audio-visual scenes; Callan et al., 2013) and responses to misfortune (e.g., immanent justice attributions; Callan et al., 2014) than those examined by van den Bos and Maas (2009). Thus, we investigated whether effortful thought is necessary for people to respond to episodes of injustice in ways more closely aligned with van den Bos and Maas's (2009) approach.

\section{Overview of the Current Research}

A long history of just-world research has shown that the strategies people employ to maintain a commitment to justice occur when people have the mental resources to consider their responses (see Hafer \& Bègue, 2005). What is not yet clear, however, is the degree to which the same effects occur intuitively - that is, when people do not have the ability, time, or motivation to think deliberatively about an episode of injustice. Lerner's (1998; Lerner \& Goldberg, 1999) theorizing, and the handful of studies reviewed above, suggest that individuals recognize, and may react to, injustices intuitively. This idea, however, has not been investigated systematically and stands in contrast to research suggesting that reactions to injustice require thoughtful deliberation (van den Bos \& Maas, 2009). Our aim was to address this inconsistency in the literature by determining whether people's reactions to injustice occur effortlessly and/or need thoughtful deliberation.

Across 7 experiments, we either (a) manipulated effortful thinking directly via time pressure or memory load manipulations (e.g., Gilbert \& Osborne, 1989; Pontari \& Schlenker, 2000; Rand et al., 2012; Roskes, Elliot, Nijstad, \& De Dreu, in press; Shalvi, Eldar, \& Bereby-Meyer, 2012; van den Bos, Peters, Bobocel, \& Ybema, 2006), (b) measured individual differences in rational and experiential thinking styles using the Rational- 
Experiential Inventory (REI; Pacini \& Epstein, 1999), or (c) primed intuitive or rational thinking (van den Bos \& Maas, 2009). Manipulating the time available for participants to make their responses is a well-documented way to produce cognitive load, as little time is available for people to think rationally, make complex links, or fully utilize controlled cognitive resources (e.g., Hernandez \& Preston, 2013; Rand et al., 2012). Similarly, placing participants under a large memory load restricts people's capacity to think carefully and deliberatively (e.g., Callan et al., 2010; Gilbert \& Osborne, 1989; Krull, Seger, \& Silvera, 2008; Pontari \& Schlenker, 2000). For example, Pontari and Schlenker (2000) demonstrated that when people are under memory load (i.e., rehearsing an 8-digit number while performing a concurrent task), they are less efficient at the demanding task of presenting themselves as an introvert when they are actually an extrovert. Finally, the REI has been shown to predict differences in behavior and cognition in regards to experiential and rational thinking styles (e.g., Pacini \& Epstein, 1999).

We then exposed participants to standard just-world threat manipulations that varied the innocence of the victim (e.g., Callan, Shead, \& Olson, 2009; Correia, Vala, \& Aguiar, 2007; Studies 1-3) or the extent to which the victim suffered (e.g., Anderson et al., 2010; Callan, Ellard, \& Nicol, 2006; Studies 4-6) before measuring participants' reactions to the events. van den Bos and Maas (2009) only measured the extent to which participants blamed the victim, but as we reviewed above, this is not the only way people can respond to perceived injustice. Indeed, Lerner and Simmons' (1966) findings suggest that when the opportunity arises, people will help versus reject an innocent victim, and subsequent research building on their findings found that participants typically only resort to derogating the victim under certain circumstances, such as when the event was real (vs. fake; Lerner, 1971) or occurred in the present (vs. the past; Simons \& Piliavin, 1972). More recently, research has shown that victim derogation in response to just world threat often occurs only for certain individuals (e.g., people with non-oppressive coping styles; Hafer \& Gosse, 2011) and in certain contexts (e.g., situations where people are focused on their long-term vs. short-term goals; Callan, Harvey, \& Sutton, 2014; Hafer, 2000a). Thus, although the phenomena of rejecting innocent victims has long been associated with just world theory, such responses are not necessarily the only means by which people make sense of innocent harm and undeserved suffering. Rather than assessing a single response to the victimization scenarios (see Hafer \& Gosse, 2010, for a critique of the single-response approach), then, for each study we assessed the degree to which participants derogated the victim, blamed the victim, were willing to help/compensate the victim, and engaged in ultimate justice reasoning (the perception that a victim will lead a more fulfilling and meaningful life in the long run; Lerner, 1980).

In short, we examined the effects of intuitive versus deliberative processing across a variety of victimization scenarios and potential responses to injustice. If people's reactions to victimization require effortful thought, we would expect the effects of just-world threat to be weaker or non-existent when participants are mentally busy, under time pressure, have a disposition to respond intuitively, or are put into an intuitive mind-set. If, however, people respond to episodes of injustice intuitively, we expect the effects of just-world threat to remain robust to manipulations and measures of thinking styles. Notably, the latter hypothesis entails the prediction that the effects of just-world threat will be largely independent of our manipulations and measurement criteria. This kind of invariance is hard to establish with conventional significance testing, so we supplement these analyses with a Bayesian approach.

\section{Study 1}

\section{STUDIES 1 TO 3: VICTIM INNOCENCE}

\section{Methods}

Participants. Participants were recruited online $(N=265,39.2 \%$ female, $0.4 \%$ 
unreported; $M_{\text {age }}=29.43$ years; $S D_{\text {age }}=9.23$ ) using Amazon's Mechanical Turk (MTurk; Buhrmester, Kwang, \& Gosling, 2011).

Materials and Procedure. Participants were recruited to participate in an online survey on impression formation. Participants first read an ostensibly real news report. The story described how a young boy sustained an electric shock when he touched a live wire while playing with friends around a construction site (Correia et al., 2007). Participants learned that the boy needed to have both his arms amputated because of the incident. In the innocent victim condition (high just-world threat), participants were given no further information about the incident. In the non-innocent victim condition (low just-world threat), participants were told that both the boy and his family had been warned about the dangers of the construction site. ${ }^{1}$

Next, participants answered a series of questions about the vignette with instructions to either take as long as they wanted (low time pressure) or to complete the questions within 70 seconds (high time pressure). The 70-second time limit was determined from pilot work as being approximately $1 S D$ faster than the average natural completion time (cf. Benson \& Beach, 1996). A countdown timer in a red box was displayed in a fixed location to the righthand side of the screen and when 70 seconds elapsed, participants were automatically redirected to the next page.

The questionnaire measured four potential reactions to the scenario: victim derogation, ultimate justice, compensation/helping, and victim blame. ${ }^{2}$ Victim derogation was assessed using three items, two of which were adapted from Hafer and Gosse (2011): "Overall, my impression of James as a person is:" $(1=$ positive to $7=$ negative $)$, "Overall, would you say that you like or dislike James as a person?" $(1=$ like to $7=$ dislike $)$, and a third from Payne, Burkley, and Stokes (2008): "Are your feelings towards James cold and unfavorable or warm and favorable?" $(1=$ cold and unfavorable to $7=$ warm and favorable; reverse coded).

Ultimate Justice reasoning was assessed using two items adapted from Anderson et al. (2010): "To what extent do you think James will find his existence fulfilling later in his life as a result of this incident?" ( $1=$ not at all fulfilling to $7=$ very fulfilling), and "To what extent do you think that in the future, James will experience his life as meaningful because of this incident?" $(1=$ not at all meaningful to $7=$ very meaningful $)$.

Helping judgments were assessed using 4 items. Two items assessed victim compensation: "Imagine that you alone had to decide how much money James received in compensation for his injuries. By selecting one of the options below, how much money do you feel he should receive in compensation?" $(1=\$ 0$ to $7=\$ 30,000+)$ and "What level of monetary compensation do you feel James should receive for what happened to him?" $(1=$ minimal compensation to $7=$ maximum compensation). Another two items emphasized helping intentions and were adapted from Steins and Weiner (1999): "Let's imagine James needs help with recovery. If you had the possibility to help James, by giving up some of your time to aid him in recovery programs, how willing would you be to do so?" $(1=$ not at all willing to $7=$ very willing) and "Imagine that in your town there are many opportunities to actively help amputees like James by collecting money from different institutions. Would you be willing to engage in this kind of help for James?" $(1=$ not at all willing to $7=$ very willing).

\footnotetext{
${ }^{1}$ All scenarios used in this paper are provided in Appendix 1.

${ }^{2}$ All measures achieved acceptable internal consistency across all studies ( $\alpha \mathrm{s}>.74$ or $\left.r \mathrm{~s}>.70\right)$. For studies that manipulated level of processing (Studies 1-2, 4-5, and 7), the internal consistencies were similar across experimental conditions (mean difference between alphas $/ r \mathrm{~s}=.00025$, range of differences was -.25 to +.14 ).
} 
Victim blaming was assessed using four items adapted from van den Bos and Maas (2009): "I believe James himself is responsible for what happened to him", "I believe James brought the accident on himself", "I believe that what has happened to James is his own fault", and "I believe James is to blame for what has happened to him" $(1=$ strongly disagree to $7=$ strongly agree). ${ }^{3}$

Finally, participants were directed to a new page where they rated how unfair they found the incident as a manipulation check, "I feel what happened to James is:" $(1=$ slightly unfair to $7=$ a great deal unfair). These same measures were used, in this order $^{4}$, for all studies in this paper, with only slight adaptations to the wording to suit each scenario. Study 2

Participants. Students and staff from the University of Essex participated in a laboratory experiment for $£ 3$ or partial course credit $\left(N=146,68.5 \%\right.$ female; $M_{\text {age }}=21.19$ years; $S D_{\text {age }}=3.69$ ).

Materials and Procedure. Participants first completed an unrelated decision-making study before completing the material for Study 2. To manipulate cognitive load, participants were given up to 20 seconds to either memorize a 2-digit (12; low load) or an 8-digit (73749265; high load) number. Participants then read a vignette that described a male pedestrian who was struck by a car while crossing the road at a pedestrian crossing (Callan, Dawtry, \& Olson, 2012). In the innocent victim condition, the driver was identified as being on a cell phone and ignoring the traffic signal when the accident occurred. In the noninnocent victim condition, the pedestrian was reported as being on a cell phone when the accident occurred. Two blame items were used for this study: the "responsible" item and the "fault" item from Study 1. A third ultimate justice item was included in this study: "To what extent do you think John will feel empty 20 years from now?" $(1=$ strongly disagree to $7=$ strongly agree; reverse coded). ${ }^{5}$

Study 3

Participants. Participants from the UK were recruited online via social media networks or the University of Essex volunteer e-mail list for the chance to win a gift voucher $\left(N=215,66.5 \%\right.$ female, $0.5 \%$ unreported; $M_{\text {age }}=23.23$ years; $\left.S D_{\text {age }}=7.21\right)$.

Materials and Procedure. We used a short form of the Rational-Experiential Inventory (REI) scale (24 items) to measure individual differences in both Rationalistic and Experiential thinking styles (Norris \& Epstein, 2007). The rationality subscale is a modified

\footnotetext{
${ }^{3}$ Some participants in the time pressure condition were not able to complete all of the questions before the time ran out and therefore missed some of the last items in this and our subsequent time pressure studies (30\%). We therefore used the average of the items participants did answer for their scores on these measures. Analyses using only participants who completed every question yielded the same main conclusions. We were concerned that because some participants did not answer all items in the time pressure conditions, the psychometric properties of these measures may have been affected. As a result, we examined the difference between the internal consistencies of our dependent measures (i.e., victim blame, derogation, helping/compensation, ultimate justice reasoning) for the studies that manipulated time pressure (Studies 1, 4, and 7) using the Feldt test (Feldt, 1969; Suen, 2009) or Fisher's r-to-z transformation. Out of the 12 comparisons, 5 reached significance. From these 5 significant comparisons, internal consistencies were higher under time pressure for 4 measures and higher under no time pressure for one measure. We therefore conclude that placing participants under time pressure did not systematically alter the psychometric properties of our dependent measures. ${ }^{4}$ The ordering was altered slightly for Studies 2 and 7. The blame items were presented after the victim derogation items for Study 2 and presented first for Study 7.

${ }^{5}$ To more closely replicate the measures used by Anderson et al. (2010), the ultimate justice items for this study referred to the victim's life specifically "20 years from now". As can be seen in Table 1, these items showed the same pattern of results as those used in Study 1, therefore the items and wording from Study 1 (linking a misfortune to future life) was used for the remaining studies.
} 
form of the Need for Cognition scale (Cacioppo \& Petty, 1982; e.g., "I have a logical mind") and the experiential thinking subscale is based on a Faith in Intuition scale (e.g., "I believe in trusting my hunches"), which have been shown to predict intuitive responses (e.g., nonoptimal responses in a gambling task; Pacini \& Epstein, 1999). Both subscales were presented on a 5-point scale $(1=$ definitely false to $5=$ definitely true $)$ and were reliable $(\alpha \mathrm{s}=$ .83 and .85 , respectively).

Next, participants read a vignette about a young woman who was severely wounded when a train caught her leg as it passed. In the innocent victim condition, the woman was crossing the tracks when the signals showed it was safe to do so. In the non-innocent victim condition, the woman jumped the gates to cross the tracks. Participants then answered the questionnaire used in Study 1. A third ultimate justice item was included and used for all other studies not using a time pressure manipulation (Studies 5 and 6): "To what extent do you think that in the long run, Lucy will find purpose in her life as a result of this incident?" $(1=$ not at all purposeful to $7=$ very purposeful; Anderson et al., 2010).

\section{Manipulation Checks}

\section{Results}

Time Pressure Manipulation. In Study 1, half the participants were placed under time pressure. We analyzed the timing data to assess if participants responded more rapidly while under a time constraint. Participants in the time pressure condition $(M=57.84, S D=$ 12.92) took significantly less time (in seconds) to answer the questionnaire than participants in the no time pressure condition $(M=84.36, S D=42.44), t(262)=6.87, p<.001, d=.85$. Participants in the time pressure condition $(M=4.94, S D=2.43)$ were also quicker to make their first response on the questionnaire than participants in the no time pressure condition $(M$ $=7.50, S D=7.98), t(262)=3.52, p=.001, d=0.43$. These results confirm that participants under time pressure (vs. no time pressure) responded to the questionnaire more rapidly, limiting the opportunity to engage in deliberative reasoning (cf. Rand et al., 2012; Shalvi et al., 2012). ${ }^{6,7}$ Importantly, these results are consistent with recent research showing that time pressure manipulations can be used successfully in online studies employing comparable time limits per item/decision (e.g., Hernandez \& Preston, 2013; Rand et al., 2012; see also Study 7).

To independently assess whether our time pressure manipulation limits people's capacity for effortful thinking, we conducted a validation study using an online sample of participants $\left(N=79,73.4 \%\right.$ female, $1.3 \%$ unreported; $M_{\text {age }}=39.91$ years; $\left.S D_{\text {age }}=12.08\right)$. Instead of answering 13 questionnaire items, we asked participants to answer 13 arithmetic problems (e.g., $987+44$ ) with two multiple-choice answers (e.g., 1041 or 1031; see Gray, Schein, \& Ward, in press). We also asked participants how challenging they found the questions, to what extent they felt they could take their time (reverse coded), and how confident they felt in their answers (reverse coded; $\alpha=0.70 ; 1=$ strongly disagree to $7=$ strongly agree). Participants were given the same instructions as Study 1 (i.e., to take as much time as needed vs. answering the questions as quickly as possible). Participants in the time pressure condition were also presented with the same countdown timer, which automatically advanced to the next page when 70 seconds had elapsed.

As with our time pressure studies (Studies 1, 4, and 7), not all participants in the time pressure condition were able to finish answering all the questions $(56 \%)$. Of the questions

\footnotetext{
${ }^{6}$ The same time pressure manipulation was used for Studies 4 and 7 . Analyses for these data also showed that participants in the no time pressure conditions took significantly longer overall ( $p \mathrm{~s}<$ $.001, d \mathrm{~s}>0.85)$ and were significantly slower to make their first response $(p \mathrm{~s}<.03, d \mathrm{~s}>0.34)$.

${ }^{7}$ In total, two participants from the no time pressure condition were excluded from these analyses for being exceptionally slow to make their first response (>10 SD above the mean).
} 
participants did answer, participants under time pressure answered significantly fewer questions correctly than participants with no time constraints (see Table 1). Similarly, considering the first four questions only, which was the minimum any one person completed, participants under time pressure (vs. no time pressure) answered fewer questions correctly. Participants also started and finished the problems quicker when under time pressure than participants who were not (cf. Studies 1, 4, and 7). In addition, participants in the time pressure condition found answering the questions significantly more difficult than participants who were not under any time pressure. Finally, only one participant left the study from the time pressure condition after starting, indicating no significant difference between conditions in terms of termination rates (Fisher's Exact Test, $p=.49){ }^{8}$ In sum, the above analyses suggest that being placed under time pressure forces people to respond quickly, disrupting their ability to respond deliberatively.

Perceived Unfairness. Across our studies participants in the innocent victim condition rated the situations as significantly more unfair than did participants in the noninnocent victim condition, all $p s<.001, d s>0.52$ (see Table 2).

\section{Cognitive Load X Victim Innocence Interactions}

Our primary analysis strategy was to examine the interaction of Victim Innocence and Cognitive Load/REI for our dependent variables across our studies and with all of the data standardized and combined into one larger analysis where appropriate (see Table 2). Analyses with the cognitive load studies revealed no significant Victim Innocence $X$ Cognitive Load interactions. That is, the effect of victim innocence on victim derogation, victim helping, and victim blaming did not vary as a function of mental busyness. Reinforcing our conclusions further, the significant effect of victim innocence on participants' reactions to the victims were individually significant at both the intuitive and deliberative levels of processing (Studies 1 and 2; $p \mathrm{~s}<.01, d \mathrm{~s}>.65$ ).

Following Aiken and West (1991), we regressed victim blame, helping, derogation, and ultimate justice reasoning onto the manipulation of victim innocence (effect coded), rationalistic thinking or experiential thinking (mean-centered), and their cross-product interaction terms. The effect of victim innocence was independent of thinking style for all but one of the dependent variables ( $p s>.10$ ). The sole exception was an interaction between victim innocence and rationalistic thinking style for ultimate justice reasoning $(B=-.68, S E=$ $.31), t(209)=2.16, p=.03$. Follow-up analyses showed that participants who were less rationalistic $(-1 S D)$ engaged in more ultimate justice reasoning for the innocent than the non-innocent victim $(B=.69, S E=.24), t(209)=2.90, p=.004$. Highly rationalistic individuals $(+1 S D)$ did not differ in their ultimate justice judgments as a function of victim innocence $(B=-.04, S E=.24), t(209)=0.15, p>.05$. This result suggests that, if anything, the less rationalistic participants are, the more they engage in ultimate justice reasoning under conditions of just-world threat. See Table 3 for the predicted values of all dependent variables as a function of thinking styles. On the whole, the lack of an interaction between victim innocence and cognitive load/REI suggests that people's reactions to innocent victims occurred effortlessly as well as rationally. That is, people react to injustice similarly at both the intuitive and deliberative level of processing.

\section{Mediation Analysis}

All dependent measures were significantly correlated with perceived unfairness (data collated across studies; see Table 4). Bootstrapping mediation analyses (Preacher \& Hayes, 2008) revealed a significant indirect effect of the victim innocence manipulation on victim

\footnotetext{
${ }^{8} \mathrm{We}$ also found that the sample sizes from our time pressure studies (Studies 1,4, and 7) were not significantly disproportionate, $\chi^{2} \mathrm{~s}<.02, p \mathrm{~s}>.89$. Therefore, participants were not more likely to terminate the experiment early if placed under time pressure.
} 
blame, derogation, helping, and ultimate justice reasoning through perceived unfairness (see Table 5). These findings highlight the mediating role of perceived unfairness in people's reactions to the suffering of innocent versus non-innocent victims across levels of mental busyness.

\section{Discussion}

Across 3 experiments, using different victimization scenarios, the innocence of a victim influenced victim blaming, derogation, and helping, but these effects were independent of manipulations of cognitive load and thinking styles. That is, people recognized and responded differently to innocent and non-innocent victims at the intuitive as well as the deliberative level of processing. Participants blamed and derogated the innocent victim less than the non-innocent victim and instead offered more help and compensation. It is, of course, not surprising that participants rated victims who brought about their own suffering as less worthy and more blameworthy than those who did not (see Haynes \& Olson, 2006; Shaver, 1985; Weiner, 1995).

Our goal, however, was not to demonstrate that these effects occur, but to directly examine how they operate under varying conditions of mental busyness or individual differences in thinking styles. van den Bos and Maas (2009) suggested that reactions to injustice only occur at the rational/deliberative level of mental processing. From this perspective, any effect of a victim's innocence on people's responses should be observed only when people are able or motivated to think rationally. This does not fit our data. That is, the effects of victim innocence were not moderated by factors that directly influence effortful thinking - indeed, victim innocence affected victim blaming, victim derogation, and judgments of helping regardless of participants' ability or proclivity to think experientially or rationally.

\section{STUDIES 4 to 6: VICTIM SUFFERING STATUS}

Across Studies 4 to 6, we aimed to confirm that our findings are applicable to another just-world threat manipulation: the degree to which a victim suffered (e.g., Anderson et al., 2010; Callan et al., 2006; Hafer, 2000a; Lerner \& Simmons, 1966). A second purpose was to employ a manipulation that actively encourages deliberative vs. intuitive thinking (van den Bos \& Maas, 2009).

\section{Study 4}

\section{Methods}

Participants. Participants were recruited online using MTurk across two time points $\left(N \mathrm{~s}=131\right.$ and 132 ; total $N=263,52.1 \%$ female, $0.8 \%$ unreported; $M_{\text {age }}=31.81$ years; $S D_{\text {age }}$ $=11.09)$. These samples did not produce significantly different time pressure by threat interactions $(p s>.25)$ and therefore were analyzed together.

Materials and Procedure. Study 4 mirrored the design of Study 1. First, participants read a vignette before answering related questions while under time pressure or not. The vignette described a young soccer player who suffered an injury (Anderson et al., 2010). In the low suffering condition (low just-world threat), the boy sprained his ankle and although this caused an inconvenience and resulted in him missing a soccer game, he soon recovered. In the high suffering condition (high just-world threat), the boy badly injured his spine and spent much of his teenage years in a wheelchair before recovering.

Participants then answered the questionnaire (per Study 1) while under time pressure (70 seconds) or not. Finally, participants responded to two manipulation check items, which were used throughout Studies 4 to 6: perceived unfairness of the accident (see Study 1) and the extent to which they believed the victim suffered ("In your opinion, how much do you believe James suffered from this incident?"; 1 = hardly suffered at all to $7=$ suffered a great deal).

Study 5 
Participants. Participants were recruited online using MTurk $(N=259,40.2 \%$ female; $M_{\text {age }}=30.11$ years; $S D_{\text {age }}=11.32$ ).

Materials and Procedure. Study 5 was identical to Study 4, with the exception that instead of manipulating time pressure, participants were instructed to respond intuitively or rationally (see van den Bos \& Maas, 2009) before answering the questionnaire. Half of the participants were told to "answer each question as intuitively and impulsively as possible, responding using your gut feelings and with the first thing that comes to mind", whereas the other half were told to respond "carefully, weighing the pros and cons" and consider what they read in "logical and analytical ways."

After completing the questionnaire, participants completed the same 5 manipulation check items used by van den Bos and Maas (2009) to assess how intuitively (vs. rationally) they responded: "I thought things through thoroughly before reacting to James's story" ( $1=$ strongly disagree to $7=$ strongly agree; reverse coded), "I weighed and pondered upon my answers to the questions about James's story before reacting" ( $1=$ strongly disagree to $7=$ strongly agree; reverse coded), "I reacted intuitively to the questions about James's story" (1 $=$ strongly disagree to $7=$ strongly agree), "I reacted impulsively to the questions about James's story by responding with the first thing that came to my mind" ( 1 = strongly disagree to $7=$ strongly agree $)$, and "I answered the questions about James's story more analytically and rationalistically OR more intuitively and impulsively" ( $1=$ very analytically and rationalistically to $7=$ very intuitively and impulsively; $\alpha=.86)$.

Study 6

Participants. Participants were recruited online using MTurk $(N=220,58.6 \%$ female; $M_{\text {age }}=33.41$ years; $S D_{\text {age }}=11.52$ ).

Materials and Procedure. Participants first completed the rational and experiential thinking style subscales of the REI as in Study 3 ( $\alpha$ s $=.87$ and .91 , respectively).

Next, participants read a scenario describing a young woman who contracted a viral infection while volunteering at a care home. In the high suffering condition, the victim was hospitalized and missed a lot of school. In the low suffering condition, she suffered only mild flu-like symptoms and did not miss any school.

\section{Manipulation Checks}

\section{Results}

Instructions Manipulation. In Study 5, we adapted a procedure from van den Bos and Maas (2009) to induce intuitive thinking or rational thinking. A 2 (high vs. low suffering) by 2 (intuitive vs. rational instructions) ANOVA confirmed that participants who were given instructions to respond intuitively reported responding significantly more intuitively $(M=$ $4.89, S D=1.14)$ than participants who were asked to respond rationally $(M=2.93, S D=$ $0.97), F(1,255)=222.11, p<.001, d=1.85$. This effect size is equivalent to that reported by van den Bos and Maas (2009; average $d=1.89)$. No other effects on the manipulation check index were significant ( $p s>.25$ ).

Perceived Unfairness/Suffering. Table 6 shows that the suffering manipulation was successful for Studies 4 to 6, with significantly greater perceived unfairness and suffering in the high suffering conditions than in the low suffering conditions, $p s<.001, d s>1.26$.

\section{Time Pressure/Mind-sets X Victim Suffering Interactions}

Our primary aim for Studies 4 to 6 was to assess if our manipulations and measurement of intuitive/deliberative thinking interacted with the manipulation of victim suffering for victim blame, derogation, helping, and ultimate justice reasoning. We tested the interactions between time pressure/mind-sets/thinking styles, and suffering status for each 
dependent measure for each study individually and with all of the data standardized and combined into one larger analysis where appropriate (see Table 6). ${ }^{9}$

Across Studies 4 to 6 , we found that participants blamed the victims less, wanted to help/compensate more, and engaged in ultimate justice reasoning more when the victim suffered a great deal versus only minimally. There were no significant interactions, with the exception of one: victim suffering significantly interacted with time pressure for victim helping in Study 4. Decomposing this interaction revealed that the effect of threat on victim helping was stronger under high load, $t(259)=9.09, p<.001, d=1.56$, than low load, $t(259)$ $=6.10, p<.001, d=1.09$. If anything, this shows that participants were more sensitive to an injustice when forced to respond rapidly (cf. Rand et al., 2012). The simple main effects of victim suffering on victim reactions from Studies 4 and 5 were significant across levels of mental processing. That is, reactions to victimization as a function of victim suffering occurred significantly at both the intuitive and deliberative levels of processing $(p \mathrm{~s}<.01, d \mathrm{~s}$ $>.51$ ). Following the same analysis strategy as Study 3 for Study 6, moderated regression analyses showed no statistically significant REI X Suffering Status interactions $(p s>.22)$. See Table 3 for the predicted values of all the dependent variables as a function of thinking styles.

\section{Mediation Analysis}

All measures significantly correlated with perceived unfairness (see Table 4).

Bootstrapping analyses revealed a significant indirect effect of the victim suffering manipulation on victim blame, derogation, helping, and ultimate justice reasoning through perceived unfairness (see Table 5), suggesting that a concern for justice is one mechanism that underlies people's reactions to the suffering of an innocent victim.

\section{Discussion}

Consistent with recent research (e.g., Anderson et al., 2010; Hafer \& Gosse, 2011; Haynes \& Olson, 2006), Studies 4-6 showed that participants opted for more pro-social reactions (i.e., victim help/compensation and ultimate justice reasoning) over victim rejection when the victim suffered a great deal versus only minimally. Although we did not observe the classic effects of victim suffering status on victim derogation and blame (Lerner \& Miller, 1978), as mentioned above, victim derogation in response to just world threat usually occurs only under certain circumstances (see Hafer, 2000a; Hafer \& Gosse, 2011). More importantly, the effects of a victim's suffering status on participants' reactions did not vary as a function of time pressure, instructions to think intuitively/rationally, or individual thinking styles, adding support for the notion that these reactions occur not only at the deliberative

\footnotetext{
${ }^{9}$ Because we did not conceptually replicate van den Bos and Maas's (2009) findings using the same manipulation of mind-sets, we suspected that the just world threat manipulation they used included details that encouraged victim blaming. In an online study $(N=122)$ we created an "innocentized" version of van den Bos and Maas's (2009) "high threat" scenario and compared it to their original high and low threat scenarios in terms of how much participants blamed the victim and how unfair and unjust they perceived the situation. In this new version, a young woman cycled home at 2 p.m. (vs. 4 a.m. in the original), took her regular route through a park (vs. a shortcut), and was not offered - and therefore did not refuse - a ride from her friends. All participants were asked to think about and respond to the scenario rationally. Participants in this study blamed the victim less $(M \mathrm{~s}=$ 1.52 and 2.82), and perceived the situation as more unfair/unjust $(M \mathrm{~s}=6.51$ and $5.71 ; p \mathrm{~s}<.01, d \mathrm{~s}>$ .74 ), when she was described as more innocent (vs. the original high threat scenario). We did not replicate van den Bos and Maas's effect of low vs. high just-world threat on victim blaming $(M \mathrm{~s}=$ 2.66 vs. $2.82 ; p=.60, d=.12$, JZS Bayes Factor $=5.09)$, nor was perceived injustice significantly different between van den Bos and Maas's low and high threat scenarios $(M \mathrm{~s}=5.49$ vs. $5.71 ; p=.46$, $d=.17$, JZS Bayes Factor $=4.46$ ). In sum, these findings support the studies reported above, where innocent (vs. non-innocent) victims are blamed less.
} 
level of processing, but also when participants are forced or have the tendency to think intuitively. Importantly, even though we successfully manipulated deliberative and intuitive mind-sets (cf. van den Bos \& Maas, 2009), participants responded equally to victims of misfortune across both conditions in Study 5 .

\section{STUDY 7: SELF-REPORTED BELIEF IN A JUST WORLD}

Study 7 examined whether mental busyness modulates the positive relation between self-reported just-world beliefs and victim blaming (see Furnham, 2003). van den Bos and Maas (2009) propose that an inconsistency between one's self-reported just-world beliefs and an observed injustice can only be resolved when people are able to think deliberatively. Therefore, the relationship between believing in a just world and victim rejection should be significantly weakened when people are less able to think deliberatively. If, however, high just-world believers' reactions to injustice occur intuitively, we would expect the correlations between just-world beliefs and reactions to the victim to hold constant regardless of mental busyness. To test these ideas, in Study 7 we measured participants' just-world beliefs before presenting them with the suffering of an innocent victim. Participants read the victimization scenario and provided their judgments of victim blaming, victim derogation, helping, and ultimate justice reasoning while under time pressure or not.

\section{Method}

Participants. Participants were recruited online using MTurk $(N=159,56 \%$ female, $1.3 \%$ unreported; $M_{\text {age }}=31.66$ years; $S D_{\text {age }}=10.77$ ).

Materials and Procedure. Participants were told they would complete two separate tasks. First, they were asked to complete the Global Belief in a Just World scale (GBJW; $\alpha=$ .90; Lipkus, 1991). Next, all participants were presented with the high suffering scenario used in Study 6 (infection at a care home). Finally, as in Studies 1 and 4, judgments of victim derogation, blame, helping, and ultimate justice reasoning were assessed while participants were under time pressure or not.

\section{Results and Discussion}

Each of our dependent measures was separately regressed onto the manipulation of time pressure (effect coded) and mean-centered GBJW scores, along with their interaction term. Consistent with previous research (Furnham, 2003), GBJW was a significant predictor of victim blaming $(B=.57, S E=.09), t(155)=6.35, p<.001$ (but did not significantly predict derogation, helping, or ultimate justice reasoning, $p s>.14$ ). See Table 3 for the predicted values of all the dependent variables as a function of GBJW. Our manipulation of time pressure did not significantly interact with GBJW for our dependent variables ( $p \mathrm{~s}>.07)$, with the exception of victim blaming $(B=-.48, S E=.18), t(155)=2.68, p=.008$. Figure 1 shows that higher GBJW scores were associated with greater victim blaming when there was no time pressure $(B=.32, S E=.13), t(155)=2.48, p=.014$, but this relation was significantly stronger under time pressure $(B=.80, S E=.12), t(155)=6.55, p<.001$.

These results suggest that individuals who are more given to blaming an innocent victim (i.e., high just-world believers) do so more strongly when their ability to engage in effortful thinking is limited. Rather than indicating that victim blaming occurs only at the deliberative level of mental processing (van den Bos \& Maas, 2009), Study 7 suggests that high just-world believers may be correcting an otherwise intuitive, negative reaction to the victim. This finding is consistent with Lerner's $(1998,2003)$ suggestion that some people's intuitive, counter-normative responses to an innocent victim's suffering (e.g., victim blaming) may be deliberatively controlled because of other values or concerns (e.g., social desirability, adhering to social norms), leading to their heightened expression when cognitive resources are not available to monitor responses (see Callan et al., 2010, for similar effects with immanent justice attributions for a random negative outcome).

\section{BAYESIAN ANALYSES}


We found no interaction between just-world threat and manipulations or measures of effortful thinking across 7 highly-powered studies ${ }^{10}$ employing different manipulations and dependent variables. This suggests that mental busyness has little effect on people's reactions to victimization. In other words, our data point to a theoretically meaningful invariance: a particular effect is impervious to manipulations that might well be expected to modulate it. As Rouder, Speckman, Sun, Morey, and Iverson (2009) have noted, identifying such invariance is crucial to scientific progress but is often difficult within the framework of conventional statistical testing, where one can reject the null hypothesis but cannot gain evidence for it, and where one should "never use the unfortunate phrase 'accept the null hypothesis"” (Wilkinson and the APA Task Force for Statistical Inference, 1999, p. 599). Criticisms of this aspect of null hypothesis significance testing have a long history (e.g., Edwards, Lindman, \& Savage, 1963; Gallistel, 2009; Greenwald, 1975; Wagenmakers, 2007) and the situation is elegantly summarized by Bakan (1966): "Even the strict repetition of an experiment and not getting significance in the same way does not speak against the results already reported in the literature...the study already reported in the literature, with a low $p$ value, is regarded as conclusive. Thus we tend to place in the archives studies with a relatively high number of Type I errors... and we act in such a fashion as to reduce the likelihood of their correction."

Partly because of this, there has been increasing interest in Bayesian inference as an alternative to conventional null hypothesis significance testing (e.g., Gallistel, 2009; Kruschke, 2010; Matthews, 2011; Rouder et al., 2009; Wagenmakers, 2007). In particular, some researchers have advocated the use of Bayes factors (e.g., Dienes, 2011; Rouder et al., 2009; Wagenmakers, Lodewyckx, Kuriyal, \& Grasman, 2010; see Kruschke, 2011, for an alternative Bayesian approach). The Bayes factor is the probability of obtaining the observed data under one hypothesis (or model) relative to the probability of obtaining the data under another hypothesis. For example, we may pit the null hypothesis $H_{0}$ against an alternative hypothesis $H_{1}$ by calculating the Bayes factor $B F\left[H_{0}: H_{1}\right]=\operatorname{Pr}\left(D \mid H_{0}\right) / \operatorname{Pr}\left(D \mid H_{1}\right)$, where $\operatorname{Pr}\left(D \mid H_{i}\right)$ is the probability of obtaining the data under hypothesis $H_{i}$. The Bayes factor provides a continuous measure of evidence; in this example, a Bayes factor of 20 means that the data are 20 times more likely under the null hypothesis than under the alternative. From Bayes' theorem, the odds of the two hypotheses given the data, $\operatorname{Pr}\left(H_{0} \mid D\right) / \operatorname{Pr}\left(H_{1} \mid D\right)$, are equal to the prior odds (i.e., the odds before the current data were collected) multiplied by the Bayes factor. In other words, the Bayes factor quantifies how we should update our beliefs in light of the data, and is therefore argued to be an obvious basis for inference.

To calculate the Bayes factor, one must specify an alternative hypothesis $H_{1}$. Typically, researchers entertain a distribution of possible alternatives to the null, some of which are judged more likely than others. For example, we may anticipate a high probability of a small-to-medium effect, a moderate probability of a large effect, and a very remote chance of a gargantuan effect. More generally, a given hypothesis will entail a set of parameters, and in advance of data collection different parameter values are assigned different prior probabilities. Calculation of the Bayes factor involves weighting the likelihood of obtaining the data with a given parameter value by the prior probability of that parameter value, across the whole of the parameter space. The prior distribution therefore influences the Bayes factor, and the choice of a prior distribution is at the researcher's

\footnotetext{
${ }^{10}$ We conducted sensitivity power analyses for the collated data from Studies 1-2 and for 4-5. For studies 1-2 the sensitivity analysis suggests $95 \%$ power to detect an effect with $f=0.18\left(\eta^{2}=.031\right)$; for studies 4-5 there is $95 \%$ power to detect an effect with $f=0.16\left(\eta^{2}=.025\right)$.
} 
disposal; it may be based on knowledge about likely values established in previous work, or it may be chosen to be minimally informative (e.g., by letting every parameter value be equally likely). Considerable effort has been spent developing "default" priors which are broadly applicable, computationally tractable, and have desirable properties; there are now "Bayesian versions" of several familiar analyses, including t-tests (e.g., Rouder et al., 2009; Wetzels, Raaijmakers, Jakab, \& Wagenmakers, 2009), correlation (e.g., Wetzels \& Wagenmakers, 2012), regression (Rouder \& Morey, 2012), and ANOVA (Rouder, Morey, Speckman, \& Province, 2012; Wetzels, Grasman, \& Wagenmakers, 2012).

We calculated Bayes factors to examine the interaction effects in our studies, using two different default priors developed for variable selection in the linear model framework. Our primary focus is on the Bayes factor calculated using a Zellner-Siow (ZS) $g$ prior (Zellner \& Siow, 1980). This is a widely-used prior with a number of desirable mathematical properties, which can be rendered in a computationally convenient form to serve as a default for many analyses based on linear models (Liang, Paulo, Molina, Clyde, \& Berger, 2008; Wetzels et al., 2012; see Appendix 2 for more details).

Table 7 shows the Bayes factors for the interactions between cognitive load and victim innocence/suffering in the studies which factorially manipulated these variables (Studies 1, 2, 4, and 5), for the interactions between victim innocence/suffering and both the rational and experiential components of the REI (Studies 3 and 6), and for the interaction between time pressure and GBJW (Study 7). Of the 36 Bayes factors, 34 are greater than 1.0, meaning that they favor the null hypothesis of no interaction effect. Wagenmakers, Wetzels, Borsboom, and van der Maas (2011) proposed a verbal classification scheme for Bayes factors (Table 8). Applying this to our results, 4 of the Bayes factors provide "anecdotal" evidence for the absence of an interaction, 27 provide "substantial" evidence and 3 demonstrate "strong" evidence. Of the two Bayes factors less than 1.0, one has a value of 0.95 , indicating that the data are almost completely uninformative with respect to the two hypotheses, and the other (for the victim blaming measure of Study 7) has a value of 0.28 , suggesting "substantial" evidence for the presence of an interaction. This is the same time pressure $x$ GBJW interaction discussed above. Repeating the analysis using a "unit information prior" for the alternative hypothesis yielded almost identical results (Table 7).

\section{GENERAL DISCUSSION}

Across 7 experiments we assessed people's reactions to injustice at varying levels of mental processing and thinking styles. Studies 1 to 3 found that the effects of victim innocence on victim rejection and willingness to help were largely independent of manipulations of mental busyness and individual differences in thinking style. Studies 4 to 7 further demonstrated the effortlessness of people's reactions to victimization with a manipulation of intuitive/rational mind-sets, the measurement of just-world beliefs, and a different just-world threat manipulation (victim suffering status). On the whole, these results point to the conclusion that rational and effortful thought is not required for people to respond to victimization. In fact, the few significant interactions we did observe were in the opposite direction from what might be expected if effortful thinking was necessary.

If effortful thinking is not necessary, then what processes underlie people's reactions to victimization? Drawing on recent single-process accounts of judgments (see Kruglanski \& Gigerenzer, 2011), we argue that both intuitive and deliberative reactions to injustice are based on the application of the same justice-related heuristics or scripts elicited by the most salient cues within the environment (see Lerner, 2003; Lerner \& Clayton, 2011). That is, people's reactions to injustice will be determined by the application of the same heuristics regardless of whether they have the time, motivation, or ability to engage in effortful thinking. Such justice-related heuristics, which Lerner (1998) argued appear very early in people's lives, may reflect notions such as "blameworthy people are bad people" (Haynes \& 
Olson, 2006) or "if a victim suffers a lot, then help/compensate" (Lerner \& Simmons, 1966). Echoing Kruglanski and Gigerenzer's (2011) sentiments about the "rule selection problem," the challenge for future research will be to determine "what these heuristics are, when they are applied, and in which situations they are successful" (pg. 101). In addition, although applying these heuristics may not require effortful deliberation, actually implementing them may do. That is, helping and compensating a victim may be more effortful to actually implement than, for example, avoiding a victim. Another potential avenue for future research, then, is to examine the role that effortful versus intuitive thinking might play in the implementation of actions associated with people's initial responses to victimization.

In light of our results, then, why did van den Bos and Maas (2009) find that participants engaged in victim blaming only when in a deliberative/rational mind-set? One possible reason is that van den Bos and Maas (2009) used a victimization scenario containing details that insinuated that the victim was in some way acting irresponsibly and was worthy of blame (i.e., a non-innocent victim; see footnote 8). Offering participants cues to blame the victim may therefore result in victim blaming becoming the most accessible and utilized response, depending on the manipulated mind-set of participants (see Hafer \& Gosse, 2010; Haynes \& Olson, 2006). Moreover, van den Bos and Maas (2009) only examined the extent to which their participants blamed the victims under different "primed" mind-sets, which limited the degree to which generalizations could be made to other potential reactions to perceived injustice and other instantiations of mental busyness. Our 7 studies used multiple scenarios over two variations of just world threat before assessing four potential reactions to the victimization scenarios. The present research therefore provides a more comprehensive account of the role that intuitive versus effortful thinking plays in people's responses to victimization.

\section{Limitations and Future Directions}

There are, of course, limitations to the current research. First, our time pressure manipulation resulted in several participants not finishing the questionnaire within the time limit. As such, the measures nearer the end of the questionnaires may have been less reliably assessed. Researchers interested in using time pressure manipulations to examine intuitive versus effortful responses to victimization might consider randomizing items across scales, calibrating time limits to individual participants' known rates of responding, or relying on other manipulations of intuitive versus effortful thinking (e.g., memory load).

Second, although we examined a number of justice-restoring strategies, this is by no means an exhaustive account of all the possible means by which people maintain a commitment to justice. For example, psychologically distancing oneself from a victim (Hafer, 2000b; Lerner, 1980) or demonizing a perpetrator (Ellard et al., 2002) have been considered means to restoring a belief in a just world. Future research should consider a range of different strategies to further assess the effortlessness of people's varied reactions to injustice. As highlighted in the current research, it is important to measure a range of different reactions to injustice because people's first "port of call" to restore justice to the situation may not necessarily involve victim rejection. Indeed, the phenomenon of rejecting innocent victims has long been associated with just world theory and has dominated much of the research literature (see Callan \& Ellard, 2010; Hafer \& Bègue, 2005), but a growing body of research has shown that when given the opportunity, people opt to help innocent victims over derogating them (cf. Lerner \& Simmons, 1966). Furthermore, victim rejection is often only found in certain circumstances (e.g., when people are focused on their long-term goal; see Hafer, 2000a) or as a function of various individual differences (e.g., for people with nonoppressive coping styles; Hafer \& Gosse, 2011; or people higher in a self-reported belief in a just world; see Study 7). Victim rejection may also occur only when participants are motivationally and emotionally engaged by a victimization context (see Lerner, 2003), which 
might have been limited in the sorts of scenarios and vignettes we used in the current research.

Finally, individual differences and the situational determinants of what strategies people employ to maintain a belief in a just world were largely not considered in the present investigation. Hafer and Gosse (2010) suggest that strategy choice and magnitude may vary as a function of ideological beliefs, justice beliefs, demographics, and coping styles. For example, Hafer and Gosse (2011) identified that individuals identified as "repressors" positively appraised an innocent victim's suffering as a means of maintaining their belief in a just world, whereas "non-repressors" devalued the victim's character. Harvey and Callan (2014) found that the more (vs. less) religious people were, the more they causally connected a victim's prior misdeeds to his current misfortune as a way of making sense of the misfortune. Therefore, future research should investigate whether individual differences and different contexts might modulate the different strategies people employ to maintain a belief in a just world under varying levels of mental processing.

\section{Conclusions}

We found that, overall, people respond to just-world threat in ways that remain robust to manipulations or measurements of deliberative and intuitive processing, showing that people respond to victimization not only when they are able to think rationally or deliberatively, but also when responding quickly, under memory load, or thinking intuitively. 


\section{References}

Aguiar, P., Vala, J., Correia, I., \& Pereira, C. (2008). Justice in our world and in that of others: Belief in a just world and reactions to victims. Social Justice Research, 21, 50-68.

Aiken, L. S., \& West, S. G. (1991). Multiple regression: Testing and interpreting interactions. Newbury Park, CA: Sage.

Anderson, J. E., Kay, A. C., \& Fitzsimons, G. M. (2010). In search of the silver lining: The justice motive fosters perceptions of benefits in the later lives of tragedy victims. Psychological Science, 21, 1599-1604.

Bakan, D. (1966). The test of significance in psychological research. Psychological Bulletin, $66,423-437$.

Benson, L., \& Beach, L. (1996). The effects of time constraints on the pre-choice screening of decision options. Organizational Behavior and Human Decision Processes, 67, 222-228.

Buhrmester, M., Kwang, T., \& Gosling, S. D. (2011). Amazon's mechanical Turk: A new source of inexpensive, yet high-quality, data? Perspectives on Psychological Science, $6,3-5$.

Cacioppo, J. T., \& Petty, R. E. (1982). The need for cognition. Journal of Personality and Social Psychology, 42, 116-131.

Callan, M. J., Dawtry, R. J., \& Olson, J. M. (2012). Justice motive effects in ageism: The effects of a victim's age on observer perceptions of injustice and punishment judgments. Journal of Experimental Social Psychology, 48, 1343-1349.

Callan, M. J., \& Ellard, J. H. (2010). Beyond victim derogation and blame: Just world dynamics in everyday life. In D. R. Bobocel, A. C. Kay, M. P. Zanna, \& J. M. Olson (Eds.). The psychology of justice and legitimacy: The Ontario Symposium (Vol. 11, pp. 53 - 77). New York: Psychology Press.

Callan, M. J., Ellard, J. H., \& Nicol, J. E. (2006). The belief in a just world and immanent justice reasoning in adults. Personality and Social Psychology Bulletin, 32, 16461658.

Callan, M. J., Ferguson, H. J., \& Bindemann, M. (2013). Eye movements to audio-visual scenes reveal expectations of a just world. Journal of Experimental Psychology: General, 142, 34-40.

Callan, M. J., Harvey, A. J., \& Sutton, R. M. (2014). Rejecting victims of misfortune reduces delay discounting. Journal of Experimental Social Psychology, 51, 41-44.

Callan, M. J., Shead, N. W., \& Olson, J. M. (2009). Foregoing the labor for the fruits: The effect of just world threat on the desire for immediate monetary rewards. Journal of Experimental Social Psychology, 45, 246-249.

Callan, M. J., Sutton, R. M., \& Dovale, C. (2010). When deserving translates into causing: The effect of cognitive load on immanent justice reasoning. Journal of Experimental Social Psychology, 46, 1097-1100.

Callan, M. J., Sutton, R. M., Harvey, A. J., \& Dawtry, R. J. (2014). Immanent justice reasoning: Theory, research, and current directions. In J. M. Olson \& M. P. Zanna (Eds.), Advances in Experimental Social Psychology (Vol. 49, pp. 105-161). London: Academic Press.

Correia, I., Vala, J., \& Aguiar, P. (2007). Victim's innocence, social categorization, and the threat of the belief in a just world. Journal of Experimental Social Psychology, 43, $31-38$.

Dienes, Z. (2011). Bayesian versus orthodox statistics: Which side are you on? Perspectives on Psychological Science, 6, 274-290. 
Edwards, W., Lindman, H., \& Savage, L. J. (1963). Bayesian statistical inference for psychological research. Psychological Review, 70, 193-242.

Ellard, J. H., Harvey, A. J., \& Callan, M. J. (in press). The Justice Motive. In C. Sabbagh \& M. Schmitt (Eds.), Handbook of Social Justice Theory and Research.

Ellard, J. H., Miller, C. D., Baumle, T., \& Olson, J. M. (2002). Just world processes in demonizing. In M. Ross \& D. T. Miller (Eds.), The justice motive in everyday life. (pp. 350-362). Cambridge, UK: Cambridge University Press.

Feldt, L. S. (1969). A test of the hypothesis that Cronbach's alpha or Kuder-Richardson coefficient twenty is the same for two tests. Psychometrika, 34, 363-373.

Furnham, A. (2003). Belief in a just world: Research progress over the past decade. Personality and Individual Differences, 34, 795-817.

Gallistel, C. R. (2009). The importance of proving the null. Psychological Review, 116, 439453.

Gilbert, D. T., \& Osborne, R. E. (1989). Thinking backwards: Some curable and incurable consequences of cognitive busyness. Journal of Personality and Social Psychology, 57, 940-949.

Goldberg, J. H., Lerner, J. S., \& Tetlock, P., E. (1999). Rage and reason: The psychology if the intuitive prosecutor. The European Journal of Social Psychology, 29, 781-795.

Gawronski, B., \& Bodenhausen, G. V. (2006). Associative and propositional processes in evaluation: An integrative review of implicit and explicit attitude change. Psychological Bulletin, 132, 692-731.

Gray, K., Schein, C., \& Ward, A. F. (in press). The myth of harmless wrongs in moral cognition: Automatic dyadic completion from sin to suffering. Journal of Experimental Psychology: General.

Greenwald, A. G. (1975). Consequences of prejudice against the null hypothesis. Psychological Bulletin, 82, 1-20.

Hafer, C. L. (2000a). Investment in long-term goals and commitment to just means drive the need to believe in a just world. Personality and Social Psychology Bulletin, 26, 10591073.

Hafer, C. L. (2000b). Do innocent victims threaten the belief in a just world? Evidence from modified Stroop task. Journal of Personality and Social Psychology, 79, 165-173.

Hafer, C., \& Bègue, L. (2005). Experimental research on just-world theory: Problems, developments, and future challenges. Psychological Bulletin, 131, 128-167.

Hafer, C. L., \& Gosse, L. (2010). Preserving the belief in a just world: When and for whom are different strategies preferred?. In D. R. Bobocel, A. C. Kay, M. P. Zanna, \& J. M. Olson (Eds.), The psychology of justice and legitimacy: The Ontario symposium. (Vol. 11, pp. 79-102). New York: Psychology Press.

Hafer, C. L., \& Gosse, L. (2011). Predicting alternative strategies for preserving a belief in a just world: The case of repressive coping style. European Journal of Social Psychology, 41, 730-739.

Harvey, A. J., \& Callan, M. J. (2014). The role of religiosity in ultimate and immanent justice reasoning. Personality and Individual Differences, 56, 193-196.

Haynes, G. A., \& Olson, J. M. (2006). Coping with threats to just-world beliefs: Derogate, blame, or with help? Journal of Applied Social Psychology, 36, 664-682.

Hernandez, I., \& Preston, J. L. (2013). Disfluency disrupts the confirmation bias. Journal of Experimental Social Psychology, 49, 178-182.

Holmes, J. G., Miller, D. T., \& Lerner, M. J. (2002). Committing altruism under the cloak of self-interest: The exchange fiction. Journal of Experimental Social Psychology, 38, $144-151$.

Jeffreys, H. (1961). Theory of probability. ${ }^{\text {rd }}$ Ed. Oxford: Clarendon Press. 
Kass, R. E., \& Wasserman, L. (1995). A reference Bayesian test for nested hypotheses and its relationship to the Schwarz criterion. Journal of the American Statistical Association, 90, 928-934.

Kruglanski, A. W. \& Gigerenzer, G. (2011). Intuitive and deliberative judgments are based on common principles. Psychological Review, 118, 97-109.

Krull, D. S., Seger, C. R., \& Silvera, D. H. (2008). Smile when you say that: Effects of willingness on dispositional inferences. Journal of Experimental Social Psychology, $44,735-742$.

Kruschke, J. K. (2010). What to believe: Bayesian methods for data analysis. Trends in Cognitive Sciences, 14, 293-300.

Kruschke, J. K. (2011). Bayesian assessment of null values via parameter estimation and model comparison. Perspectives on Psychological Science, 6, 299-312.

Lerner, M. J. (1971). Observer's evaluation of a victim: Justice, guilt, and veridical perception. Journal of Personality and Social Psychology, 20, 127-135.

Lerner, M. J. (1980). The belief in a just world: A fundamental delusion. New York: Plenum Press.

Lerner, M. J. (1998). The two forms of belief in a just world. In L. Montada \& M. J. Lerner (Eds.), Responses to Victimizations and Belief in a Just World. (pp. 247-269). New York: Plenum press.

Lerner, M. J. (2003). The justice motive: Where social psychologists found it, how they lost it, and why they may not find it again. Personality and Social Psychology Review, 7, 388-399.

Lerner, M. J., \& Clayton, S. (2011). Justice and self-interest: Two fundamental motives. New York: Cambridge University Press.

Lerner, M. J., \& Goldberg, J. H. (1999). When do decent people blame victims? The differing effects of the explicit/rational and implicit/experiential cognitive systems. In S. Chaiken \& Y. Trope (Eds.), Dual-process theories in social psychology. (pp. 627640). New York: The Guilford Press.

Lerner, M. J., \& Simmons, C. H. (1966). Observers reaction to the 'innocent victim': Compassion or rejection? Journal of Personality and Social Psychology, 4, 203-210.

Liang, F., Paulo, R., Molina, G., Clyde, M. A., \& Berger, J. O. (2008). Mixtures of $g$ priors for Bayesian variable selection. Journal of the American Statistical Association, 103, 410-423.

Lipkus, I. (1991). The construction and preliminary validation of a global belief in a just world scale and the exploratory analysis of the multidimensional belied in a just world scale. Personality and Individual Differences, 11, 1171-1178.

Loseman, A., \& van den Bos, K. (2012). A self-regulation hypothesis of coping with an unjust world: Ego-depletion and self-affirmation as underlying aspects of blaming of innocent victims. Social Justice Research, 25, 1-13.

Maas, M., \& van den Bos, K. (2009). An affective-experiential perspective on reactions to fair and unfair events: Individual differences in affect intensity moderated by experiential mindsets. Journal of Experimental Social Psychology, 45, 667-675.

Matthews, W. J. (2011). What might judgment and decision making research be like if we took a Bayesian approach to hypothesis testing? Judgment and Decision Making, 6, 843-856.

Norris, P., \& Epstein, S. (2007). A short form of an inventory for measuring intuitiveexperiential and analytical-rational thinking styles, and the surprisingly strong mediation by self-esteem of the strong relation between an analytical-rational thinking style and adjustment. Manuscript submitted for publication.

Pacini, R., \& Epstein, S. (1999). The relation of rational and experiential information 
processing styles to personality, basic beliefs, and the ratio-bias phenomenon. Journal of Personality and Social Psychology, 76, 972-987.

Payne, B. K., Burkley, M. A., \& Stokes, M. B. (2008). Why do implicit and explicit attitude tests diverge? The role of structural fit. Journal of Personality and Social Psychology, 94, 16-31.

Pontari, B. A., \& Schlenker, B. R. (2000). The influence of cognitive load on selfpresentation: Can cognitive busyness help as well as harm social performance? Journal of Personality and Social Psychology, 78, 1092-1108.

Preacher, K. J., \& Hayes, A. F. (2008). Asymptotic and resampling strategies for assessing and comparing indirect effects in multiple mediator models. Behavior Research Methods, 40, 879-891.

Rand, D. G., Greene, J. D., \& Nowak, M. A. (2012). Spontaneous giving and calculated greed. Nature, 489, 427-430.

Roskes, M., Elliot, A. J., Nijstad, B. A., De Dreu, C. K. W. (in press). Time pressure undermines performance more under avoidance than approach motivation. Personality and Social Psychology Bulletin.

Rouder, J. N., \& Morey R. D. (2012). Default Bayes factors for Model Selection In Regression. Multivariate Behavioral Research. 47, 877-903.

Rouder, J. N., Morey R. D., Speckman P. L., \& Province J. M. (2012). Default Bayes factors for ANOVA designs. Journal of Mathematical Psychology. 56, 356-374.

Rouder, J. N., Speckman, P. L., Sun, D., Morey, R. D., \& Iverson, G. (2009). Bayesian $t$ tests for accepting and rejecting the null hypothesis. Psychonomic Bulletin \& Review, 16, 225-237.

Shaver, K. G. (1985). The attribution of blame: Causality, responsibility, and blameworthiness. New York: Springer-Verlag.

Shalvi, S., Eldar, O., Bereby-Meyer, Y. (2012). Honesty requires time (and lack of justifications). Psychological Science, 23, 1264-1270.

Simons, C. W., \& Piliavin, J. A. (1972). Effect of deception on reactions to a victim. Journal of Personality and Social Psychology, 21, 56-60.

Steins, G., \& Weiner, B. (1999). The influence of perceived responsibility and personality characteristics on the emotional and behavioral reactions to people with AIDS. The Journal of Social Psychology, 139, 487-495.

Suen, H. K. (2009). Feldt test to compare two Cronbach Alpha values [Measurement instrument]. Retrieved from http://suen.educ.psu.edu/ hsuen/papers.html

van den Bos, K., \& Maas, M. (2009). On the psychology of the belief in a just world: Exploring experiential and rationalistic paths to victim blaming. Personality and Social Psychology Bulletin, 35, 1567-1578.

van den Bos, K., Peters, S. L., Bobocel, D. R., \& Ybema, J. F. (2006). On preferences and doing the right thing: Satisfaction with advantageous inequity when cognitive processing is limited. Journal of Experimental Social Psychology, 42, 273-289.

van Prooijen, J-W., \& van de Veer, E. (2010). Perceiving pure evil: The influence of cognitive load and prototypical evilness on demonizing. Social Justice Research, 23, 259-271.

Wagenmakers, E-J. (2007). A practical solution to the pervasive problems of $p$ values. Psychonomic Bulletin \& Review, 14, 779-804.

Wagenmakers, E-J., Lodewyckx, T., Kuriyal, H., \& Grasmna, R. (2010). Bayesian hypothesis testing for psychologists: A tutorial on the Savage-Dickey method. Cognitive Psychology, 60, 158-189. 
Wagenmakers, E-J., Wetzels, R., Borsboom, D., \& van der Maas, H. L. J. (2011). Why psychologists must change the way they analyze their data: The case of Psi: Comment on Bem (2011). Journal of Personality and Social Psychology, 100, 426-432.

Warner, R. H., Vandeursen, M. J., \& Pope, A. R. D. (2012). Temporal distance as a determinant of just world strategy. European Journal of Social Psychology, 42, 276284.

Weiner, B. (1995). Judgments of responsibility: A foundation for a theory of social conduct. New York: Guilford.

Wetzels, R., Grasman, R.P.P.P., \& Wagenmakers, E.-J. (2012). A Default Bayesian Hypothesis Test for ANOVA Designs. The American Statistician, 66, 104-111.

Wetzels, R., Raaijmakers, J. G. W., Jakab, E., \& Wagenmakers, E.-J. (2009). How to quantify support for and against the null hypothesis: A flexible WinBUGS implementation of a default Bayesian $\mathrm{t}$ test. Psychonomic Bulletin \& Review, 16, 752760.

Wetzels, R., \& Wagenmakers, E.-J. (2012). A default Bayesian hypothesis test for correlations and partial correlations. Psychonomic Bulletin \& Review, 19, 1057-1064.

Wilkinson, L., \& the APA Task Force on Statistical Inference. (1999). Statistical methods in psychology journals: Guidelines and explanations. American Psychologist, 54, 594 604.

Zellner, A., \& Siow, A. (1980). Posterior odds ratios for selected regression hypotheses. In J.M. Bernardo, M.H. DeGroot, D.V . Lindley, \& A.F.M. Smith (Eds.), Bayesian statistics (pp. 585-603). Valencia: University Press. 
Table 1

Descriptive and inferential statistics for the online time pressure manipulation validation study.

\begin{tabular}{|c|c|c|c|c|c|}
\hline & $\begin{array}{c}\text { Time } \\
\text { pressure } \\
\text { mean }(\mathrm{SD})\end{array}$ & $\begin{array}{c}\text { No time } \\
\text { pressure } \\
\text { mean (SD) }\end{array}$ & $t$ & $p$ & $d$ \\
\hline $\begin{array}{l}\text { Proportion of total } \\
\text { (13) questions correct }\end{array}$ & $\begin{array}{c}0.86 \\
(0.19)\end{array}$ & $\begin{array}{c}0.98 \\
(0.05)\end{array}$ & 3.67 & $<.001$ & 0.82 \\
\hline $\begin{array}{l}\text { First four questions } \\
\text { correct }\end{array}$ & $\begin{array}{c}3.37 \\
(0.94)\end{array}$ & $\begin{array}{c}3.85 \\
(0.36)\end{array}$ & 3.01 & .004 & 0.67 \\
\hline $\begin{array}{l}\text { Time (in seconds) to } \\
\text { start the questions }\end{array}$ & $\begin{array}{c}5.76 \\
(3.12)\end{array}$ & $\begin{array}{c}7.39 \\
(3.93)\end{array}$ & 2.01 & .048 & 0.46 \\
\hline $\begin{array}{l}\text { Time (in seconds) to } \\
\text { finish the questions }\end{array}$ & $\begin{array}{l}62.84 \\
(8.56)\end{array}$ & $\begin{array}{l}110.17 \\
(49.59)\end{array}$ & 5.80 & $<.001$ & 1.33 \\
\hline $\begin{array}{l}\text { Perceived difficulty of } \\
\text { task }\end{array}$ & $\begin{array}{c}4.39 \\
(1.09)\end{array}$ & $\begin{array}{c}2.61 \\
(0.84)\end{array}$ & 8.14 & $<.001$ & 1.84 \\
\hline
\end{tabular}


Table 2

Descriptive and inferential Statistics for Studies 1 to 3.

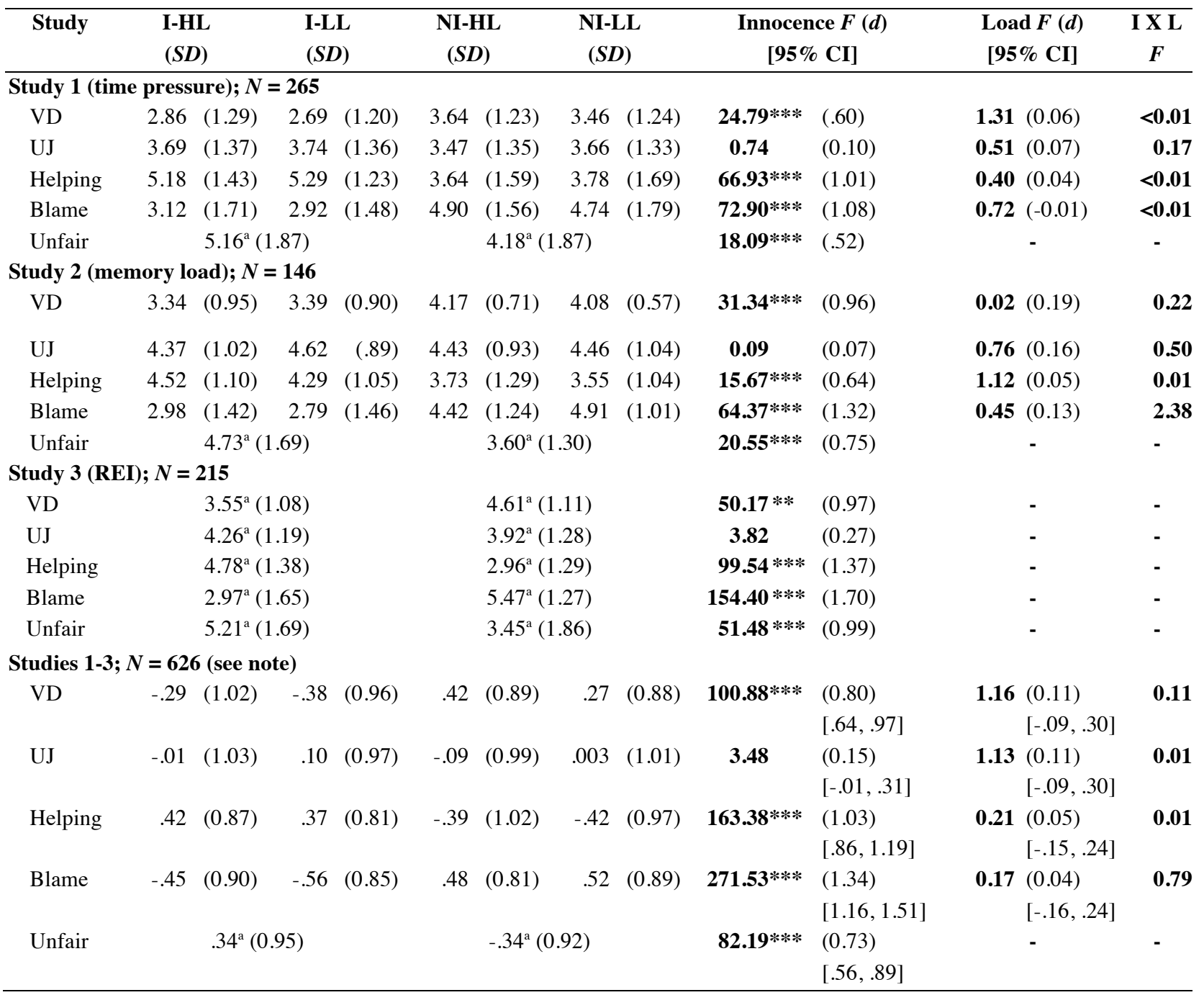

Note. VD = Victim Derogation; UJ = Ultimate Justice; I = Innocent; NI = Non-innocent; HL = High load; LL = Low load; $d=$ Cohen's $\mathrm{d}$; 95\% CI = 95\% Confidence Intervals around $d$. Effect sizes coded as negative if group differences are inconsistent with direction from the combined analysis. For the combined data set, data was standardized and combined before separate ANOVAs were run for each main effect and interaction. The REI data is therefore only represented for the main effect of innocence, but not for the main effect of cognitive load or the interaction.

$* p<.05 \quad * * p<.01 \quad * * * p<.001 \quad{ }^{a}=$ Innocence level means 
Table 3

Predicted values for victim derogation, ultimate justice reasoning (UJ), victim helping, victim blame as a function of rationalistic and experiential thinking style for Studies 3 and 6 (upper section) and as a function of global belief in a just world (GBJW) for Study 7 (lower section).

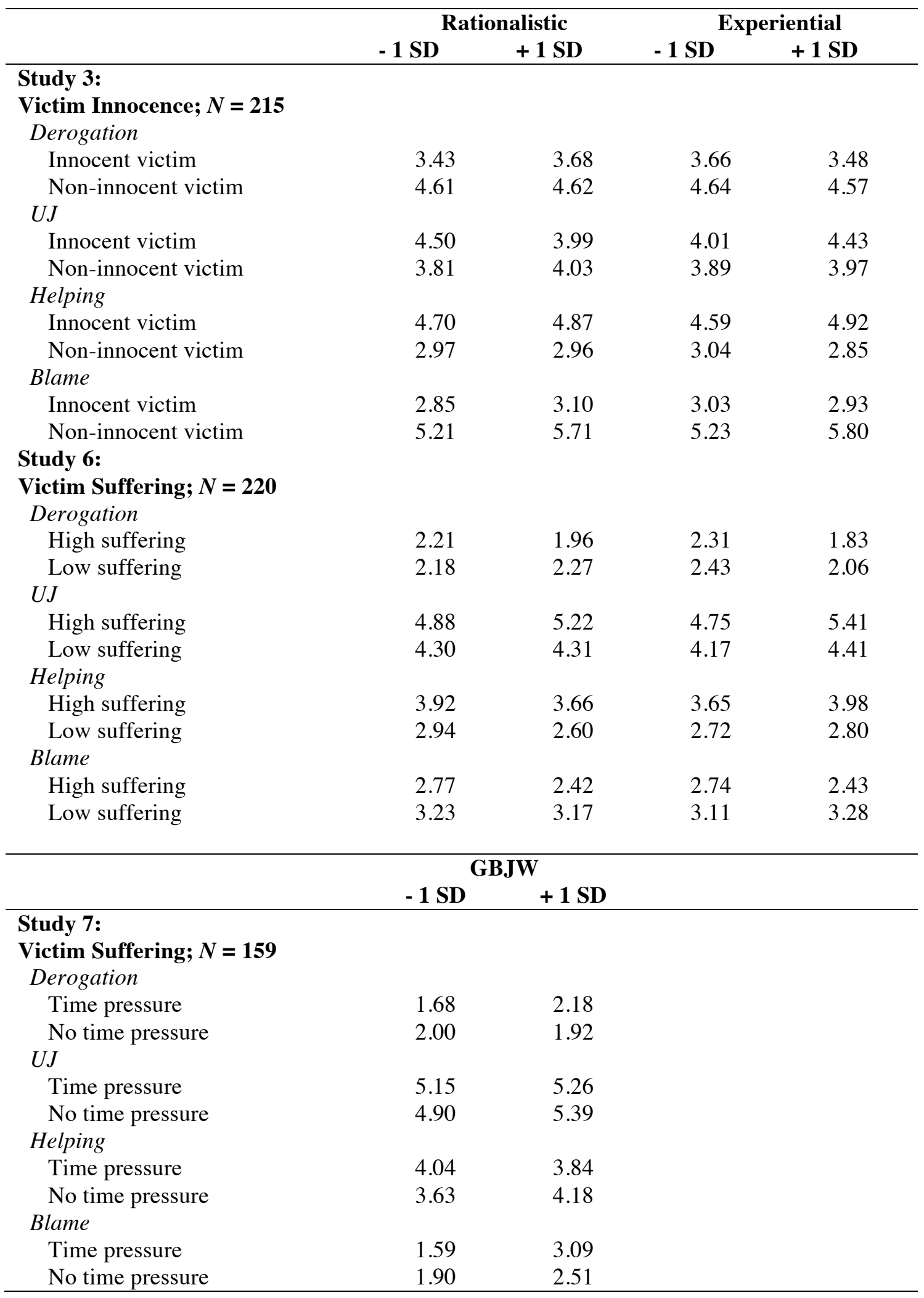


Reactions to Victimization 25

Table 4

Correlations among the relevant standardized and combined measures for Studies 1-3 (above the diagonal) and Studies 4-6 (below the diagonal).

\begin{tabular}{cccccc}
\hline & Derogation & UJ & Helping & Blame & Unfairness \\
\hline Derogation & - & -.26 & -.52 & .59 & -.46 \\
UJ & -.43 & - & .16 & -.17 & .13 \\
Helping & -.25 & .45 & - & -.63 & -.49 \\
Blame & .38 & -.22 & -.28 & - & -.57 \\
Unfair & -.12 & .35 & .56 & -.25 & - \\
Suffer & -.21 & .46 & .59 & -.25 & .72 \\
& & & & & \\
\hline
\end{tabular}

Note. All correlations are significant at $p<.01$. 
Table 5

Bootstrapped indirect effects of the just-world threat manipulations on victim derogation, ultimate justice reasoning, victim helping, and victim blame through perceived unfairness.

\begin{tabular}{|c|c|c|c|c|}
\hline & \multirow[b]{2}{*}{ Point Estimate } & \multirow[b]{2}{*}{ SE } & \multicolumn{2}{|c|}{$\begin{array}{r}95 \% \text { BCA } \\
\text { Confidence Interval }\end{array}$} \\
\hline & & & LL & UL \\
\hline \multicolumn{5}{|l|}{ Study 1-3 (victim innocence) } \\
\hline Victim Derogation & -.26 & .04 & -.35 & -.18 \\
\hline Ultimate Justice & .08 & .03 & .02 & .15 \\
\hline Victim Helping & .26 & .04 & .19 & .34 \\
\hline Victim Blame & -.29 & .04 & -.37 & -.21 \\
\hline \multicolumn{5}{|c|}{ Study 4-6 (victim suffering status) } \\
\hline Victim Derogation & -.14 & .06 & -.25 & -.03 \\
\hline Ultimate Justice & .24 & .06 & .14 & .35 \\
\hline Victim Helping & .51 & .05 & .41 & .61 \\
\hline Victim Blame & -.24 & .06 & -.36 & -.13 \\
\hline
\end{tabular}

Note $. \mathrm{BCA}=$ Bias-corrected and accelerated. $\mathrm{SE}=$ Standard error. $\mathrm{LL}=$ Lower limit. $\mathrm{UL}=\mathrm{Upper}$ limit. Ten thousand bootstrapped resamples were used for each test. 
Table 6

Descriptive and inferential statistics for Studies 4-6.

\begin{tabular}{|c|c|c|c|c|c|c|c|c|c|c|c|c|}
\hline Study & \multicolumn{2}{|c|}{$\begin{array}{c}\text { HS-HL } \\
(S D)\end{array}$} & \multicolumn{2}{|c|}{$\begin{array}{l}\text { HS-LL } \\
(\text { SD) }\end{array}$} & \multicolumn{2}{|c|}{$\begin{array}{c}\text { LS-HL } \\
(S D)\end{array}$} & \multicolumn{2}{|c|}{$\begin{array}{c}\text { LS-LL } \\
(S D)\end{array}$} & \multicolumn{2}{|c|}{$\begin{array}{c}\text { Suffering } F(d) \\
{[95 \% \mathrm{CI}]}\end{array}$} & $\begin{array}{c}\text { Load } F(d) \\
{[95 \% \mathrm{CI}]}\end{array}$ & \multirow[t]{2}{*}{$\underset{F}{S \mathbf{X} L}$} \\
\hline \multicolumn{12}{|c|}{ Study 4 (time pressure); $N=263$} & \\
\hline VD & 2.36 & $(1.23)$ & 2.38 & $(1.05)$ & 2.71 & $(1.08)$ & 2.39 & $(1.02)$ & 1.75 & $(0.17)$ & $1.27(0.14)$ & 1.61 \\
\hline UJ & 5.48 & $(1.25)$ & 5.49 & $(1.23)$ & 4.30 & $(1.36)$ & 4.57 & $(1.22)$ & $45.10 * * *$ & $* *(0.83)$ & $\mathbf{0 . 7 6}(0.11)$ & 0.75 \\
\hline Helping & 4.72 & $(1.53)$ & 4.37 & $(1.46)$ & 2.49 & $(1.33)$ & 2.86 & $(1.30)$ & $115.39 * * *$ & * $\quad(1.32)$ & $\mathbf{0 . 0 1}(0.03)$ & 4.38 \\
\hline Blame & 2.57 & $(1.52)$ & 2.48 & $(1.27)$ & 2.90 & $(1.62)$ & 2.79 & $(1.36)$ & 3.01 & $(0.22)$ & $\mathbf{0 . 3 0}(0.07)$ & 0.01 \\
\hline Unfair & \multicolumn{4}{|c|}{$4.96^{\mathrm{a}}(1.51)$} & \multicolumn{3}{|c|}{$2.73^{\mathrm{a}}(1.54)$} & & $141.02 * * *$ & $* * \quad(1.46)$ & - & - \\
\hline Suffer & \multicolumn{4}{|c|}{$6.02^{\mathrm{a}}(1.14)$} & \multicolumn{3}{|c|}{$2.82^{\mathrm{a}}(1.50)$} & & \multicolumn{2}{|c|}{$380.77 * * * \quad(2.41)$} & - & - \\
\hline \multicolumn{13}{|c|}{ Study 5 (mind-set instructions); $N=259$} \\
\hline VD & 2.50 & $(1.04)$ & 2.35 & $(1.03)$ & 2.68 & $(1.28)$ & 2.64 & $(1.15)$ & 2.77 & $(0.21)$ & $\mathbf{0 . 4 6}(0.08)$ & 0.12 \\
\hline UJ & 5.32 & $(1.13)$ & 5.55 & $(0.95)$ & 4.26 & $(1.46)$ & 4.33 & $(1.44)$ & $52.81 * * *$ & $* * \quad(0.90)$ & $0.98(0.10)$ & 0.24 \\
\hline Helping & 4.16 & $(1.55)$ & 4.57 & $(1.48)$ & 2.71 & $(1.13)$ & 2.75 & $(1.14)$ & $95.92 * * *$ & $* * \quad(1.22)$ & $1.81(0.12)$ & 1.19 \\
\hline Blame & 2.28 & $(0.93)$ & 2.10 & $(1.31)$ & 2.87 & $(1.35)$ & 2.96 & $(1.36)$ & $22.00 * * *$ & $* * \quad(0.58)$ & $\mathbf{0 . 0 8}(0.02)$ & 0.74 \\
\hline Unfair & 5.43 & $(1.43)$ & 5.42 & $(1.40)$ & 2.97 & $(1.37)$ & 2.74 & $(1.64)$ & $198.39 * * *$ & $* \quad(1.76)$ & $\mathbf{0 . 4 4}(0.08)$ & 0.33 \\
\hline Suffer & 6.29 & $(0.84)$ & 6.09 & $(1.08)$ & 3.13 & $(1.31)$ & 2.98 & $(1.73)$ & $384.59 * * *$ & $* * \quad(2.44)$ & $1.12(0.11)$ & 0.02 \\
\hline \multicolumn{13}{|c|}{ Study 6 (REI); $N=220$} \\
\hline VD & \multicolumn{4}{|c|}{$2.09^{\mathrm{a}}(1.03)$} & \multicolumn{4}{|c|}{$2.23^{\mathrm{a}}(1.14)$} & 0.81 & $(0.12)$ & - & - \\
\hline UJ & \multicolumn{4}{|c|}{$5.04^{\mathrm{a}}(1.21)$} & \multicolumn{4}{|c|}{$4.30^{\mathrm{a}}(1.45)$} & $16.72 * *$ & $* *(0.55)$ & - & - \\
\hline Helping & \multicolumn{4}{|c|}{$3.80^{\mathrm{a}}(1.35)$} & \multicolumn{4}{|c|}{$2.76^{\mathrm{a}}(1.22)$} & $35.66^{* * *}$ & $* \quad(0.80)$ & - & - \\
\hline Blame & \multicolumn{4}{|c|}{$2.60^{\mathrm{a}}(1.42)$} & \multicolumn{4}{|c|}{$3.20^{\mathrm{a}}(1.45)$} & $9.56 * *$ & $(0.42)$ & - & - \\
\hline Unfair & \multicolumn{4}{|c|}{$4.72^{\mathrm{a}}(1.59)$} & \multicolumn{4}{|c|}{$2.74^{\mathrm{a}}(1.55)$} & $87.71 * *$ & $* * \quad(1.26)$ & - & - \\
\hline Suffer & \multicolumn{4}{|c|}{$5.40^{\mathrm{a}}(1.27)$} & & $2.32^{\mathrm{a}}$ & $(1.32)$ & & $310.14 * *$ & $* * \quad(2.38)$ & - & - \\
\hline tudies 4-6; & $=742$ & (see note) & & & & & & & & & & \\
\hline VD & -.06 & $(1.02)$ & -.12 & $(0.93)$ & .18 & $(1.05)$ & .01 & $(0.98)$ & $5.20 *$ & $\begin{array}{l}(0.17) \\
{[.02, .31]}\end{array}$ & $\begin{aligned} & 1.63 \\
& (0.11) \\
& {[-.06, .28] }\end{aligned}$ & 0.44 \\
\hline UJ & .35 & $(0.86)$ & .44 & $(0.80)$ & -.47 & $(1.02)$ & -.34 & $(0.97)$ & $109.99 * * *$ & $\begin{array}{l}(0.77) \\
{[.62, .92]}\end{array}$ & $\begin{aligned} 1.50 & (0.11) \\
& {[-.06, .28] }\end{aligned}$ & 0.07 \\
\hline Helping & .52 & $(0.95)$ & .54 & $(0.91)$ & -.60 & $(0.75)$ & -.48 & $(0.74)$ & $231.95 * * *$ & $\begin{array}{l}(1.12) \\
{[.96,1.27]}\end{array}$ & $\begin{aligned} \mathbf{0 . 7 5} & (0.08) \\
& {[-10, .25] }\end{aligned}$ & 0.47 \\
\hline Blame & -.15 & $(0.89)$ & -.24 & $(0.95)$ & .20 & $(1.08)$ & .20 & $(1.00)$ & $30.31 * * *$ & $\begin{array}{l}(0.41) \\
{[.26, .56]}\end{array}$ & $\begin{aligned} & 0.27 \\
& (0.05) \\
& {[-.13, .22] }\end{aligned}$ & 0.23 \\
\hline Unfair & & $.60^{\mathrm{a}}(0.7$ & & & & $-.60^{\mathrm{a}}(0$. & & & $415.29 * * *$ & $\begin{array}{l}(1.50) \\
{[1.33,1.66]}\end{array}$ & - & - \\
\hline Suffer & & $.77^{\mathrm{a}}(0.5$ & & & & $-.77^{\mathrm{a}}(0$ & & & $1082.88 * * *$ & $\begin{array}{l}(2.42) \\
{[2.23,2.61]}\end{array}$ & - & - \\
\hline
\end{tabular}

Note . VD = Victim Derogation; UJ = Ultimate Justice; HS = High suffering; LS = Low suffering; HL = High load/rational mind-set; LL = Low load/intuitive mind-set; $d=$ Cohen's d. For the combined data set, data was standardized and combined before separate ANOVAs were run for each main effect and interaction. The REI data is therefore only represented for the main effect of suffering, but not for the main effect of cognitive load or the interaction.

$* p<.05 \quad * * p<.01 \quad * * * p<.001 \quad{ }^{a}=$ Suffering level means 
Table 7

Bayes factors with the ZJS prior and the unit information prior for the Just-World Threat $X$ Cognitive Load/REI interactions.

\begin{tabular}{|c|c|c|c|c|c|c|c|c|}
\hline & \multicolumn{4}{|c|}{ Zellner-Siow prior } & \multicolumn{4}{|c|}{ Unit information prior } \\
\hline & Blame & Derogation & Helping & $\mathbf{U J}$ & Blame & Derogation & Helping & $\begin{array}{l}\mathbf{U J} \\
\end{array}$ \\
\hline \multicolumn{9}{|l|}{$\begin{array}{l}\text { Study 1-3 (victim } \\
\text { innocence) }\end{array}$} \\
\hline Study 1 & 11.89 & 10.76 & 11.42 & 9.50 & 15.75 & 16.30 & 16.18 & 14.98 \\
\hline Study 2 & 2.84 & 7.62 & 8.05 & 6.05 & 3.68 & 10.85 & 12.04 & 9.42 \\
\hline Study 3 EXP & 3.23 & 9.63 & 4.26 & 5.96 & 3.85 & 13.72 & 5.54 & 9.24 \\
\hline Study 3 RAT & 9.98 & 7.39 & 9.86 & 0.95 & 12.01 & 10.48 & 12.93 & 1.44 \\
\hline \multicolumn{9}{|l|}{$\begin{array}{l}\text { Study } 4-7 \text { (victim } \\
\text { suffering status) }\end{array}$} \\
\hline Study 4 & 9.93 & 4.64 & 1.41 & 7.64 & 15.59 & 7.23 & 1.83 & 11.13 \\
\hline Study 5 & 7.35 & 9.65 & 6.60 & 9.87 & 11.13 & 15.16 & 8.89 & 14.23 \\
\hline Study 6 EXP & 7.30 & 4.98 & 9.90 & 6.39 & 11.23 & 7.77 & 14.46 & 9.68 \\
\hline Study 6 RAT & 4.56 & 8.88 & 8.01 & 5.07 & 6.98 & 13.73 & 11.71 & 7.55 \\
\hline Study 7 & 0.28 & 1.80 & 1.71 & 5.18 & 0.37 & 2.75 & 2.62 & 8.02 \\
\hline $\begin{array}{l}\text { Studies 1-2 } \\
\text { collated }\end{array}$ & 9.75 & 12.90 & 13.79 & 12.90 & 13.36 & 19.25 & 20.11 & 20.20 \\
\hline $\begin{array}{l}\text { Studies 4-5 } \\
\text { collated }\end{array}$ & 12.83 & 11.65 & 13.46 & 15.11 & 19.96 & 18.37 & 18.08 & 22.02 \\
\hline
\end{tabular}


Table 8

Interpretation of Bayes factors suggested by Wagenmakers, Wetzels, Borsboom and van der Maas (2011).

\begin{tabular}{ll}
\hline Bayes factor, $\mathbf{B F}_{\mathbf{0 1}}$ & Interpretation \\
\hline$>100$ & Extreme evidence for $\mathrm{H}_{0}$ \\
$30-100$ & Very strong evidence for $\mathrm{H}_{0}$ \\
$10-30$ & Strong evidence for $\mathrm{H}_{0}$ \\
$3-10$ & Substantial evidence for $\mathrm{H}_{0}$ \\
$1-3$ & Anecdotal evidence for $\mathrm{H}_{0}$ \\
1 & No evidence \\
$1 / 3-1$ & Anecdotal evidence for $\mathrm{H}_{1}$ \\
$1 / 10-1 / 3$ & Substantial evidence for $\mathrm{H}_{1}$ \\
$1 / 30-1 / 10$ & Strong evidence for $\mathrm{H}_{1}$ \\
$1 / 100-1 / 30$ & Very strong evidence for $\mathrm{H}_{1}$ \\
$\leq 1 / 100$ & Extreme evidence for $\mathrm{H}_{1}$ \\
\hline
\end{tabular}




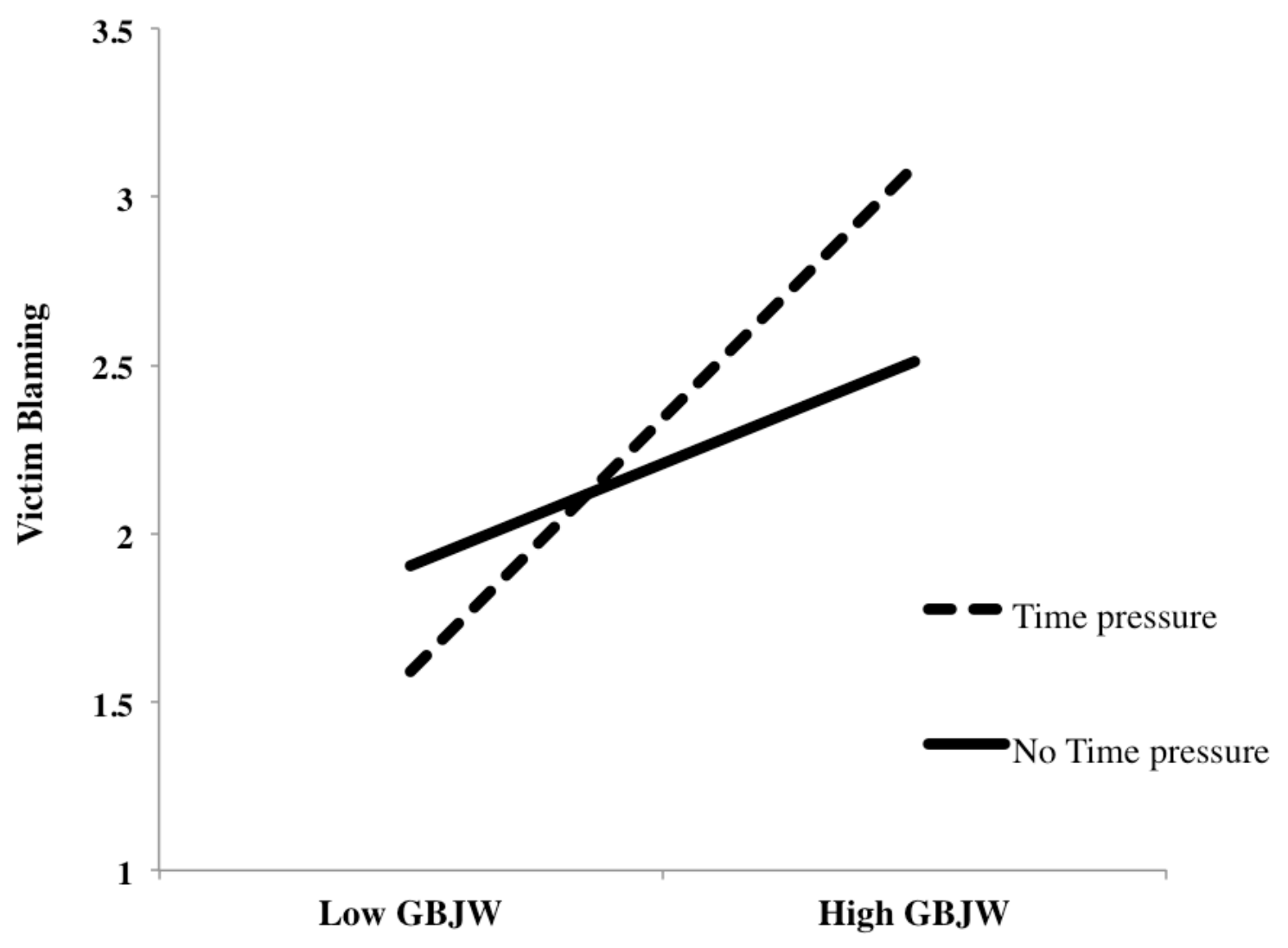

Figure 1. Relation between global belief in a just world (GBJW) (Mean +/- 1 SD) and victim blaming as a function of time pressure. 


\section{Appendix 1}

The scenarios used for each study.

\begin{tabular}{l} 
Innocent \\
\hline Study 1 In a tragic incident, the fun of innocent child's \\
play turned into sorrow when an eight-year-old \\
boy lost both his arms in a lethal electric shock. \\
The incident happened shortly before 3pm \\
Sunday afternoon when young James Wilson \\
was playing ball with a few friends near his \\
family home. \\
The ball went astray into a nearby house under \\
construction and unfortunately this house was \\
not sufficiently protected. James went to collect \\
the ball and sustained his injuries when he \\
grabbed hold of an exposed cable for support, \\
causing an intense electric current to surge \\
through his body. \\
As a consequence, James lost function in both \\
his arms and medical staff had no choice but to \\
amputate them. Due to this life-changing event, \\
James can no longer carry out everyday \\
activities without assistance, such as opening \\
doors and eating or drinking.
\end{tabular}

Study 2 A young man was hospitalised this morning after being struck by a Ford Fiesta as he used the pedestrian crossing on Dunmow High Street. John Banford, 22, was taken by ambulance to Broomfield Hospital in Chelmsford suffering from serious concussion. The accident is still under investigation, but one witness indicated that the driver of the Ford Fiesta was using a mobile phone at the time of the accident.

A young man was hospitalised this morning after being struck by a Ford Fiesta as he used the pedestrian crossing on Dunmow High Street. John Banford, 22, was taken by ambulance to Broomfield Hospital in Chelmsford suffering from serious concussion. The accident is still under investigation, but one witness indicated that John Banford did not observe the stop sign at the crossing and was using a mobile phone at the time of the accident.
Study 3 Young woman suffers major injuries after incident with train.

At 16:35 GMT, Lucy Taylor, 18, was hit by an oncoming train, while crossing a railway line close to her home.

"The barriers were up, the signals weren't on and we could hear nothing coming, so it looked clear to go", stated Kate Walsh, who was with Ms. Taylor at the time. Ms. Taylor was the first
Young, drunk woman suffers major injuries after incident with train.

At 16:35 GMT, Lucy Taylor, 18, was hit by an oncoming train, while crossing a railway line close to her home.

"The barriers were down and the signals were on. The girls were messing around by the barriers and were obviously intoxicated...one girl thought it would be a good idea to jump the 
to cross, just as a train was rapidly approaching from a sharp bend to the left. As the train passed, it caught Ms. Taylor's left leg and her face was badly wounded as she fell.

Ms. Taylor was rushed to hospital via an air ambulance, where they were unable to save the sight in one eye but successfully amputated her left leg at the knee. barrier and run across the tracks before the train", stated Kate Walsh, one onlooker present at the time. Ms. Taylor attempted to cross, just as a train was rapidly approaching from a sharp bend to the left. As the train passed, it caught Ms. Taylor's left leg and her face was badly wounded as she fell.

Ms. Taylor was rushed to hospital via an air ambulance, where they were unable to save the sight in one eye but successfully amputated her leg at the knee.

\section{High Suffering}

Studies James_249: I had a relatively normal childhood. $4 \& 5$ I played soccer from a young age and went to a suburban elementary school, where I had a number of close friends.

At the age of fifteen, I was playing for an amateur soccer league, run by the American Soccer Association (ASA), when an accident on the field brought my own teammate's cleat down on the back of my calf. My leg was severely broken and the fall also caused damage to my spine. My soccer career was finished, and over the next several years, I underwent dozens of surgeries to correct the damage to my leg and spine, and was confined to a wheelchair for much of my teenage years. I was unable to attend high school with the rest of my peers and had few friends. At the age of eighteen, I finally received treatment that allowed me to walk again and I was able to leave my wheelchair behind when I went off to university.

\section{Low Suffering}

James_249: I had a relatively normal childhood. I played soccer from a young age and went to a suburban elementary school, where I had a number of close friends.

At the age of fifteen, I was playing for an amateur soccer league, run by the American Soccer Association (ASA), when an accident on the field brought my own teammate's cleat down on the back of my calf. I suffered a mild sprain to my ankle that caused me to miss the next game, which happened to be the cup final. The sprained ankle also prevented me from walking to school, which was a mild inconvenience for a short period. However, I made a full, natural recovery soon after the incident and enjoyed the rest of my teenage years with my friends. I continued playing for the soccer team for 3 years until the age of eighteen, when I went off to university.

\section{Studies Jenny_249: I have always wanted to be a nurse.}

6 \& 7 When I was 17, I worked at the local care home for the elderly. I really enjoyed my time there, although it wasn't without its difficulties.

About 4 months into the job I caught a nasty viral infection from one of the new patients. At first I just thought I had a headache, but my symptoms grew worse and worse. I couldn't keep any food or liquids down and suffered from severe dehydration, which resulted in me being hospitalized. I was put on a drip and had to stay under observation for several weeks, while I built my strength back up. Unfortunately, I missed a lot of high school while I was recovering and struggled to catch up when I returned. The next couple years at high school
Jenny_249: I have always wanted to be a nurse. When I was 17 , I worked at a local care home for the elderly. I really enjoyed my time there, although it wasn't without its difficulties.

About 4 months into the job I caught an infection from one of the new patients. At first I had a headache, and then I felt like I had a mild cold. I felt a bit under the weather for a day or so, but I still attended high school as usual. I recovered quickly and was back to full strength in no time at all. I carried on the next couple of years at high school as usual. I kept on top of my workload and had plenty of time to socialize. Now at age 20, I am in my first year of an adult nursing degree. 
Reactions to Victimization 33

were hard work; keeping on top of my workload left little time for socializing. Now at age 20, I have fully recovered and I am in my first year of an adult nursing degree. 


\section{Appendix 2}

Here we briefly summarize the calculation of the Bayes factors reported in Table 7 of the main text. This summary closely follows Liang et al. (2008), who offer a much more detailed discussion (for other introductions to this area, see Wetzels et al., 2012; Rouder \& Morey, 2012.)

For a given analysis, we have a set of $n$ responses. We model these data with conventional linear regression. Under model $M_{\gamma}$, the response vector $\mathbf{Y}$ data is given by $\mathbf{Y}=\mathbf{1}_{n} \alpha+\mathbf{X}_{\gamma} \boldsymbol{\beta}_{\gamma}+\boldsymbol{\varepsilon}$, where $\mathbf{1}_{n}$ is a vector of $n$ ones, $\alpha$ is the intercept, $\mathbf{X}_{\gamma}$ is the centred design matrix, $\boldsymbol{\beta}_{\gamma}$ is a vector of regression coefficients, and $\boldsymbol{\varepsilon}$ is a vector of normally distributed errors with precision (the inverse of variance) denoted $\phi$. In the null model $M_{\text {null }}$, the $\boldsymbol{\beta}_{\gamma}$ values are all zero. $\alpha$ and $\phi$ are location/scale parameters common to both the null and alternative models.

To calculate Bayes factors we must specify a prior distribution for the model parameters. Zellner (1986, as cited in Liang et al., 2008) suggested the following $g$ prior:

$$
\begin{gathered}
p\left(\alpha, \phi \mid M_{\gamma}\right)=\frac{1}{\phi} \\
\boldsymbol{\beta}_{\gamma} \mid \phi, M_{\gamma} \sim \operatorname{Normal}\left(0, \frac{g}{\phi}\left(\mathbf{X}_{\gamma}^{T} \mathbf{X}_{\gamma}\right)^{-1}\right)
\end{gathered}
$$

Equation 1 specifies an uninformative "Jeffreys prior" for the location/scale parameters (Jeffreys, 1961). Of more interest is the prior for the regression coefficients in Equation 2. Consider, for example, a model with a single covariate. From Equation 2, the prior probability distribution for the regression coefficient is normally distributed with variance $g$. Setting $g$ to be small corresponds to prior belief that the regression coefficient is likely to take a small absolute value; setting $g$ to be very large means a highly diffuse prior probability distribution for the regression coefficient, where large coefficients are judged similarly likely to small ones. Different suggestions have been offered regarding the choice of $g$. One simple option is to set $g=n$, the number of observations. With this "unit information" prior, the prior provides the same amount of information about the parameter as is provided by a single observation (Kass \& Wasserman, 1995).

One advantage of this approach is that we can write an analytic expression for the Bayes factor:

$$
B F\left[M_{\gamma}: M_{\text {null }}\right]=(1+g)^{\left(n-k_{\gamma}-1\right) / 2}\left[1+g\left(1-R_{\gamma}^{2}\right)\right]^{-(n-1) / 2}
$$

Here $R_{\gamma}^{2}$ is the unadjusted R-squared value from the regression model and $k_{\gamma}$ is the number of regression coefficients for model $M_{\gamma}$.

To compare nested models, one calculates the Bayes factors pitting each model against the null model with no covariates and then calculates the ratio of these Bayes Factors. For example, to compare a model that includes only additive effects of two predictors with one that includes an interaction term, one can calculate the Bayes factor as:

$$
B F\left\lfloor M_{\text {additive }}: M_{\text {full }}\right\rfloor=B F\left[M_{\text {additive }}: M_{\text {null }}\right] / B F\left\lfloor M_{\text {full }}: M_{\text {null }}\right\rfloor
$$

With this formulation, values greater than 1 indicate that the data are more likely under the additive model than under the full model. For example, a Bayes factor of 3 means that the data are 3 times more likely under the model that assumes no interaction effect. To 
calculate the Bayes factors with unit information priors in Table 7, we used the $R^{2}$ values from linear models with and without interaction terms to calculate the Bayes factors as per questions (3) and (4). Note that in the main text, we refer to the additive model that omits an interaction term as the "null hypothesis" and the full model that includes the interaction as the "alternative", to emphasize our interest in presence or absence of an interaction.

The unit information prior is convenient, but it has a number of drawbacks. For example, as $R^{2}$ tends to 1 and the evidence for the full model goes to infinity, the Bayes factor converges to an upper limit rather than tending to infinity - the so-called "information paradox" (Liang et al., 2008). Zellner and Siow (1980) suggested an alternative $g$ prior which avoids some of these problems and which puts a multivariate Cauchy prior on the regression coefficients. Rather than taking a fixed value for the $g$ parameter, the Zellner-Siow approach puts an Inverse-Gamma $(1 / 2, \mathrm{n} / 2)$ prior on $g$. The Bayes factor is then:

$$
B F\left[M_{\gamma}: M_{n u l l}\right]=\int_{0}^{\infty}(1+g)^{\left(n-1-k_{\gamma}\right) / 2}\left[1+\left(1-R_{\gamma}^{2}\right) g\right]^{-(n-1) / 2} \pi(g) d g
$$

where

$$
\pi(g)=\frac{(n / 2)^{1 / 2}}{\Gamma(1 / 2)} g^{-3 / 2} e^{-n /(2 g)}
$$

To calculate the Bayes factors with Zellner-Siow priors in Table 7 of the main text, we numerically evaluated the integral in Equation 3 using the $R^{2}$ values from models with/without interaction terms, and calculated $B F\left[M_{\text {additive }}: M_{\text {full }}\right\rfloor=B F\left[M_{\text {additive }}: M_{\text {null }}\right] / B F\left[M_{\text {full }}: M_{\text {null }}\right\rfloor$, as before. 